$$
\text { ORNL/TM-2007/186 }
$$

\title{
2006/07 Field Testing of Cellulose Fiber Insulation \\ Enhanced with Phase Change Material
}

July 2007 



\title{
ORNL/TM-2007/186
}

\section{6/07 Field Testing of Cellulose Fiber Insulation \\ Enhanced with Phase Change Material}

Date published: July 2007

Jan Kośny, Ph.D., David Yarbrough, Ph.D. P.E., William Miller, Ph.D., Thomas Petrie, Ph.D., Phillip Childs, and Azam Mohiuddin Syed, Ph.D.

Oak Ridge National Laboratory

Douglas Leuthold

Advanced Fiber Technologies

Bucyrus, $\mathrm{OH}$

\author{
Prepared by \\ Oak Ridge National Laboratory \\ Oak Ridge, Tennessee 37831-6283 \\ managed by \\ UT-BATTELLE, LLC \\ for the \\ U.S. DEPARTMENT OF ENERGY \\ Under contract DE-AC05-00OR22725
}





\section{Contents}

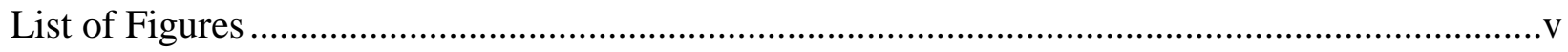

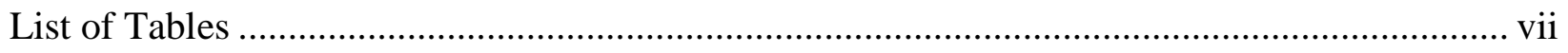

Abbreviations, Acronyms, and Initialisms....................................................................... ix

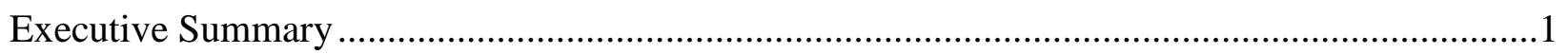

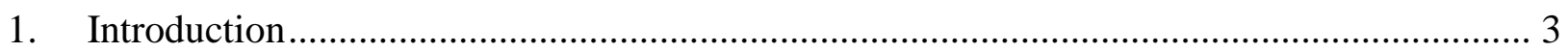

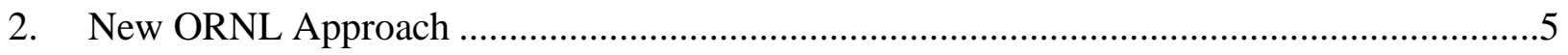

3. Lessons from Past PCM Testing in Building Envelopes ..............................................6

4. Field Test Facilities Used for Experimental Evaluation ................................................9

5. Summary of the Oak Ridge Field Test Results......................................................11

6. Summary of the Charleston, South Carolina, Field Test Results ...................................20

7. Optimum Climatic and Thermal Conditions for PCM in Cooling-Dominated

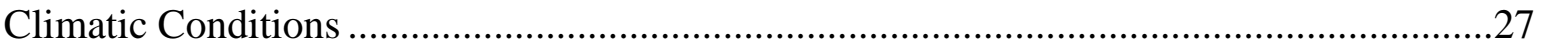

8. Basic Costs Associated with Production of PCM-Enhanced Cellulose Insulation...............31

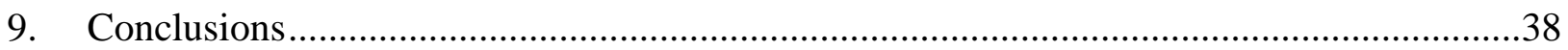

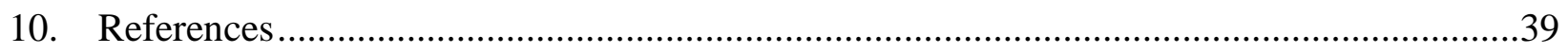





\section{Figures}

1. PCM as part of the interior surface of the building envelope.............................................. 5

2. PCM used as an integral part of the building thermal envelope.......................................... 6

3. Calorimetric data for microencapsulated PCM used during ORNL field experiment ........... 8

4. Scanning electron microscope images of PCM-cellulose blend.......................................... 8

5. Heat flux measured during the dynamic hot-box experiment performed on a $2 \times 6$ wood stud wall containing PCM-enhanced cellulose insulation. ......................................... 9

6. ORNL test wall containing PCM-enhanced cellulose insulation .......................................10

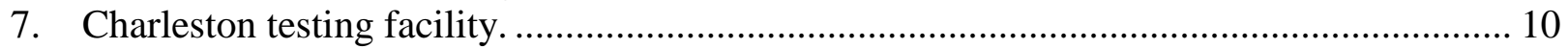

8. Installation of cellulose insulation in the Charleston Testing Facility.................................. 11

9. Measured solar radiation on the south-facing wall of the ORNL test facility...................... 12

10. Ambient air temperatures recorded during the PCM field experiment. ............................. 12

11. Exterior wall surface temperatures measured during the PCM field experiment................ 13

12. Comparison of ambient air temperatures and exterior wall surface temperatures recorded during the PCM field experiment .................................................................14

13. Instrumentation of the test walls.......................................................................... 15

14. Comparison of temperatures recorded inside the cavities of tested walls.......................... 16

15. Comparison of PCM melting and freezing temperatures recorded on two different days .. 17

16. Comparison of surface heat fluxes recorded during the ORNL field experiment that took place during a sunny week of April 2006 .............................................................17

17. Comparison of surface heat fluxes recorded during the sunny week of December 2006. .. 19

18. Surface heat fluxes recorded during the break week between 2006 and 2007................... 20

19. Weekly cooling load reductions recorded during the ORNL field experiment for the PCM wall

20. Weekly heating load reductions recorded during the ORNL field experiment

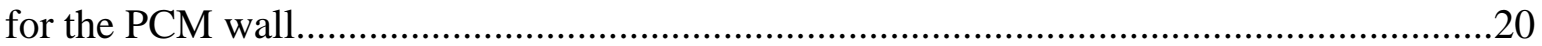

21. Measured solar radiation on the northwest-facing wall of the Charleston test facility....... 21

22. Interior and ambient air temperatures recorded during the PCM field experiment

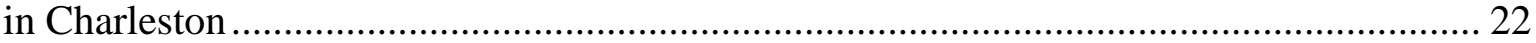

23. Exterior wall surface temperatures measured during the Charleston field experiment....... 24

24. Comparison of temperatures recorded inside the cavities of tested walls during the

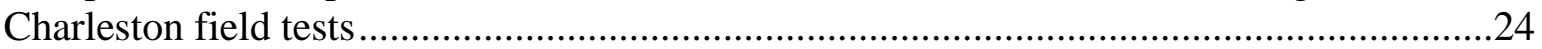

25. Comparison of temperature profiles recorded during July 2006 in Charleston.................... 25

26. Average monthly temperatures recorded in the center of the wall cavity in the Charleston PCM wall. .25

27. Comparison of the maximum peak-hour heat fluxes recorded during July 2006

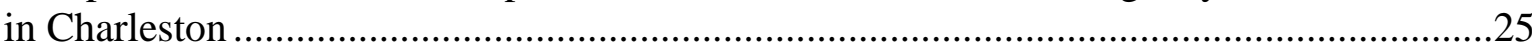

28. Surface heat fluxes recorded during June 2006 ............................................................... 27

29. Average monthly values of total hemispheric radiation incident on the vertical wall surface, used for the optimization of PCM in a cooling-dominated mode ...................28

30. Monthly averages between maximum and minimum ambient temperatures $\left(\mathrm{T}_{\mathrm{mm}}\right)$............ 31

31. Monthly averages between maximum and minimum ambient temperatures $\left(\mathrm{T}_{\mathrm{mm}}\right)$............. 31

32. Solid lines show the best months for the use of PCM-enhanced cellulose insulation.......... 30

33. Predicted number of optimum months for application of PCM-enhanced cellulose insulation 
34. Correlations between wall R-values and whole-building heating and cooling loads generated for a one story residential house by a series of whole-building energy simulations

35. Approximate correlations between whole-building heating loads and wall R-values computed for a one story residential house.

36. Approximate correlations between whole-building cooling loads and wall R-values computed for a one story residential home.....

37. Comparative costs of installing PCM-enhanced cellulose insulation and thermally equivalent fiber insulation and XPS foam sheathing. Q

(1) . .38 


\section{Tables}

1. Reduction of wall-generated cooling peak-hour load recorded on the Charleston PCM wall, during summer months 2006

2. Cost of PCM-enhanced cellulose for a blend of 10\% PCM by weight .................................32

3. Cost of PCM-enhanced cellulose for a blend of $20 \%$ PCM by weight

4. Example annual loads generated for one-story rancher located in Atlanta, containing $2 \times 4$ walls......

5. Example annual loads generated for one-story rancher located in Atlanta, containing $2 \times 4$ walls

6. Baseline and adjusted cooling loads (in MBY/year) for the scenario considered ..................36

7. R-value equivalents and $\mathrm{R}$-value differences calculated for the scenario considered ............37

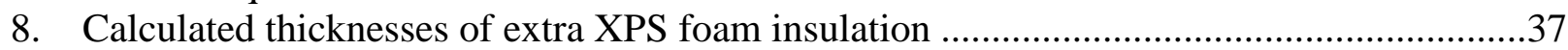

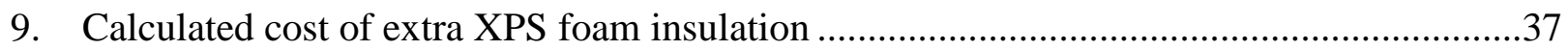





\section{Abbreviations, Acronyms, and Initialisms}

$\begin{array}{ll}\text { DOE } & \text { U.S. Department of Energy } \\ \text { ORNL } & \text { Oak Ridge National Laboratory } \\ \text { OSB } & \text { oriented strand board } \\ \text { PCM } & \text { phase change material } \\ \text { XPS } & \text { extruded polystyrene }\end{array}$





\section{6/07 Field Testing of Cellulose Fiber Insulation Enhanced with Phase Change Material}

Jan Kośny, Ph.D., David Yarbrough, Ph.D. P.E., William Miller, Ph.D., Thomas Petrie, Ph.D., Phillip Childs, and Azam Mohiuddin Syed, Ph.D.

Oak Ridge National Laboratory, Oak Ridge, TN

Douglas Leuthold

Advanced Fiber Technologies, Bucyrus, $\mathrm{OH}$

\section{EXECUTIVE SUMMARY}

The use of organic phase change materials (PCMs) to enhance the performance of thermal insulation in the building envelope was studied at Oak Ridge National Laboratory during 20062007. PCMs reduce heat flow across an insulated region by absorbing and desorbing heat (charging and discharging) in response to ambient temperature cycles. The amount of heat that can be stored in PCMs is directly related to the heat of fusion of the material, which was approximately $52 \mathrm{Btu} / \mathrm{lb}$ for the microencapsulated paraffinic material used in this research. The PCMs store energy and alter the temperature gradient through the insulated cavity because they remain at a nearly constant temperature during the melting and solidifying stages.

Results are reported for both laboratory-scale and full-size building elements in the field. Mixtures of paraffinic PCMs and conventional loose-fill cellulose insulation were evaluated in a guarded hot box facility to demonstrate heat flow reductions when one side of a test wall is subjected to a temperature increase. The laboratory work showed reductions in heat flow of about $40 \%$ due to the presence of approximately $22 \mathrm{wt} \%$ PCM in the insulation. The level of savings realized depends on the geographical location and time of year.

Field testing of wall cavities insulated with cellulose containing PCM was completed in Charleston, South Carolina, and Oak Ridge, Tennessee. Test walls in both locations were instrumented to provide temperature and heat flow data over a period of several months. Cooling-load reductions and peak-hour load reductions were observed at both sites. Cooling load reductions ${ }^{*}$ averaged $42 \%$ in the summer tests at the Oak Ridge site, with savings occasionally spiking to $80 \%$. A heating load reduction ${ }^{*}$ of $16 \%$ was observed during the last quarter of 2006. In the Oak Ridge experiment, the internal air temperature was set almost equal to the melting point of the PCM used $\left(78^{\circ} \mathrm{F}\right)$. This helped to maximize energy savings. In the Charleston experiment, the internal air temperature was about $10^{\circ}$ lower than the PCM melting point, which resulted in lower overall energy performance. Results from the Charleston site showed a 5\% reduction in cooling load during the summer months and a $30 \%$ reduction in peak-hour cooling loads.

\footnotetext{
* In this work, summarized internal heat fluxes (with heat flow directed inside the building) are called "cooling loads." Summarized external heat fluxes (with heat flow directed outside the building) are called "heating loads."
} 
Peak-hour load reductions observed at Charleston site:

$\begin{array}{llcc}\text { June } & \text { July } & \text { August } & \text { September } \\ 30 \% & 29 \% & 31 \% & 18 \%\end{array}$

Reductions in heating and cooling loads observed at Oak Ridge site:

Cooling Load Reduction

$\begin{array}{ccc}\text { Spring } & \text { Summer } & \text { Fall } \\ 65 \% & \mathbf{4 2 \%} & 75 \%\end{array}$

Heating Load Reduction

$\begin{array}{ccc}\text { Spring } & \text { Summer } & \text { Fall } \\ 10 \% & 50 \% & \mathbf{1 6 \%}\end{array}$

The load reductions documented by this study clearly show the potential for energy savings that can be achieved with PCMs. The insulation systems that were studied contained uniformly distributed PCM, which in some cases was not fully utilized. Optimization of the PCM content and placement are expected to result in savings greater than those observed in this study. The use of PCM with cellulose insulation holds promise, as the addition of a dry component to the insulation can be readily achieved without altering the manufacturing process.

One of the important findings coming from this study is that for the material configurations considered, the melting temperature of the PCM should be as close as possible to the temperature of the interior air of the building. This should be investigated in more detail during the following research.

Preliminary economic analysis of an application of the PCM-enhanced insulation in residential buildings shows a potential for cost reductions in comparison with traditional installation methods using foam sheathing. Several cost scenarios for microencapsulated PCM were considered (ranging from $\$ 1.15$ to $\$ 5.00$. per $\mathrm{lb}$ ). It was found that even for the most expensive PCMs, application of PCM-enhanced cellulose insulation can be, overall, significantly less expensive than foam sheathing - providing equivalent energy benefits and no extra effort to adjust window and door openings to the non-typical wall thicknesses. 


\title{
2006/07 Field Testing of Cellulose Fiber Insulation Enhanced with Phase Change Material
}

\author{
Jan Kośny, Ph.D., David Yarbrough, Ph.D. P.E., William Miller, Ph.D., Thomas Petrie, Ph.D., \\ Phillip Childs, and Azam Mohiuddin Syed, Ph.D. \\ Oak Ridge National Laboratory, Oak Ridge, TN \\ Douglas Leuthold \\ Advanced Fiber Technologies, Bucyrus, $\mathrm{OH}$
}

\section{INTRODUCTION}

Most recent improvements in building envelope technologies suggest that in the near future, residences will be routinely constructed to operate with very low heating and cooling loads. In that light, the application of novel building materials containing active thermal components (e.g., phase change materials [PCMs,] sub-venting, radiant barriers, and integrated hydronic systems) is like a final step in achieving relatively significant heating and cooling energy savings from technological improvements in the building envelope.

It is expected that optimized building envelope designs using PCMs for energy storage can effectively bring notable savings in energy consumption and reductions in peak hour power loads. During 2006/07, a research team at Oak Ridge National Laboratory (ORNL) performed a series of laboratory and field tests of several wall and roof assemblies using PCM-enhanced cellulose insulation. This report summarizes the test results from the perspective of energy performance. The ORNL team is working on both inorganic and organic PCMs; this report discusses only paraffinic PCMs. A limited economical analysis also is presented.

PCMs have been tested as a thermal mass component in buildings for at least 40 years. Most of the research studies found that PCMs enhanced building energy performance. In the case of the application of organic PCMs, problems such as high initial cost and PCM leaking (surface sweating) have hampered widespread adoption. Paraffinic hydrocarbon PCMs generally performed well, with the exception that they increased the flammability of the building envelope.

During 2003, Oak Ridge National Laboratory (ORNL) established a research team for the development and testing of new types of building materials enhanced with phase-change materials (PCMs) that could perform thermally as massive components of a building envelope. We expected that a new generation of PCM-enhanced building components could have a high potential for successful adoption in U.S. buildings because of their ability to reduce spaceconditioning energy consumption and peak loads. Other anticipated advantages were improvement of occupant comfort, compatibility with traditional wood and steel framing technologies, and potential for application in retrofit projects. 
Most current studies (Feustel 1995; Tomlinson, Jotshi, and Goswami 1992; Kosny, Gawin, and Desjarlais 2001) demonstrated that the application of thermal mass in well-insulated buildings could generate heating and cooling energy savings of up to $25 \%$ in residential buildings in the United States. Considering that new PCM-enhanced building envelope components could be installed in about $10 \%$ of both new and existing U.S. homes, the potential for energy savings would be between 0.2 and 0.5 quad/year.

In traditional applications, PCMs were installed directly on interior building surfaces. One of the applications investigated in past years was a gypsum board impregnated with non-encapsulated PCM. One of the main reasons for failure of that material was its relatively high flammability. In the ORNL research project, paraffinic PCM was placed inside building envelopes as part of the wall cavity insulation. Two forms of PCM application were considered by the ORNL research team: dispersed PCM in cellulose insulations and concentrated applications of PCM in frame walls and residential attics. To ensure sufficient fire resistance of the new material, smoldering combustion tests were performed on PCM-enhanced cellulose insulation in accordance with ASTM C739. The cellulose-PCM blend passed the smoldering combustion test [Kosny, Yarbrough, and Wilkes 2006]. Novel microencapsulation formulas were tested as well. Improved microcapsule-skin materials with a higher melting point and with added fire retarders are currently being tested in an attempt to improve flame resistance.

Within this project, the development of new PCM microcapsules that are highly flame resistant or nonflammable is now advanced. Two PCM companies are independently working on this issue (Microtek, USA, and BASF, Germany). At the Advanced Fiber Technology plant and research and development laboratory in Ohio, several blends of cellulose and PCM were tested according to the ASTM C-739 standard specification-E-970. During these tests, two types of skin materials for the microcapsules were tested (acrylic and melamine skins). To reduce damage to the PCM micro-pellets, the PCM will be added to the production line after the fiberizer in the next test production runs. In addition, the ORNL-Microtek team is planning to test three approaches: (1) use a paraffin wax core and deposit a flame-retardant material on the capsule surface during drying (Microtek patent), (2) use a fatty acid ester core (lower in cost and less flammable) and deposit a flame retarder on the capsule surface during drying, and (3) reduce the particle size of the microencapsulated PCM to 3-6 microns (from 15 microns) and then spray a dry slurry of microencapsulated PCM with a flame-retardant additive to produce 30-50 micron aggregates.

In the longer term, the following additional tasks are planned:

1. Encapsulate a flame-retardant material and then blend both types of capsules.

2. Develop a replacement for the melamine wall that is more durable and flame resistant.

3. Incorporate a flame retarder into the PCM prior to encapsulation.

4. Incorporate a flame retarder into the new shell chemistry during encapsulation.

The ORNL PCM project team has already developed a long-term research program proposal for continuation of the research in this field. The future research will focus on three basic areas:

1. Theoretical optimization of the cellulose-PCM blends for application in residential buildings. This part of the study was initiated in June 2007 and is mostly based on transient finite 
difference modeling and whole-building Energy Plus simulations, followed with the analysis of the climate patterns.

2. Full-house demonstrations with Building America team members. A first joint demonstration project with Habitat for Humanity and Steven Winters Associates is in the developmental stage now.

3. A project initiated in April 2007 to improve PCM technology (by adding fire retardants and applying new capsule materials and new encapsulation methods) to ensure that PCMenhanced insulation will pass required fire testing in the near future: ASTM C739 standard fire requirements (Critical Radiant Flux E 970) for cellulose insulation.

\section{NEW ORNL APPROACH}

In traditional applications, PCMs were used to stabilize the temperature of the building interior. Thus the best locations for the PCM were in interior building surfaces of walls, ceilings, or floors. As shown in Figure 1, PCMs concentrated in gypsum board interacted mostly with the interior of the building. The energy storage capacity of the PCM-impregnated gypsum boards was used to reduce interior space temperature swings and solar gains through glazing. In this working scenario, in most cases, PCM materials had to be discharged by the building's heating, ventilation, and air-conditioning system. Thus the only energy benefits associated with the traditional PCM configuration were peak-hour load savings and peak load shifting. In addition, the location of the PCMs on internal surfaces was not very practical because of the relatively small temperature fluctuations in the building interior. Under such conditions, a very long time was required to discharge the stored energy.

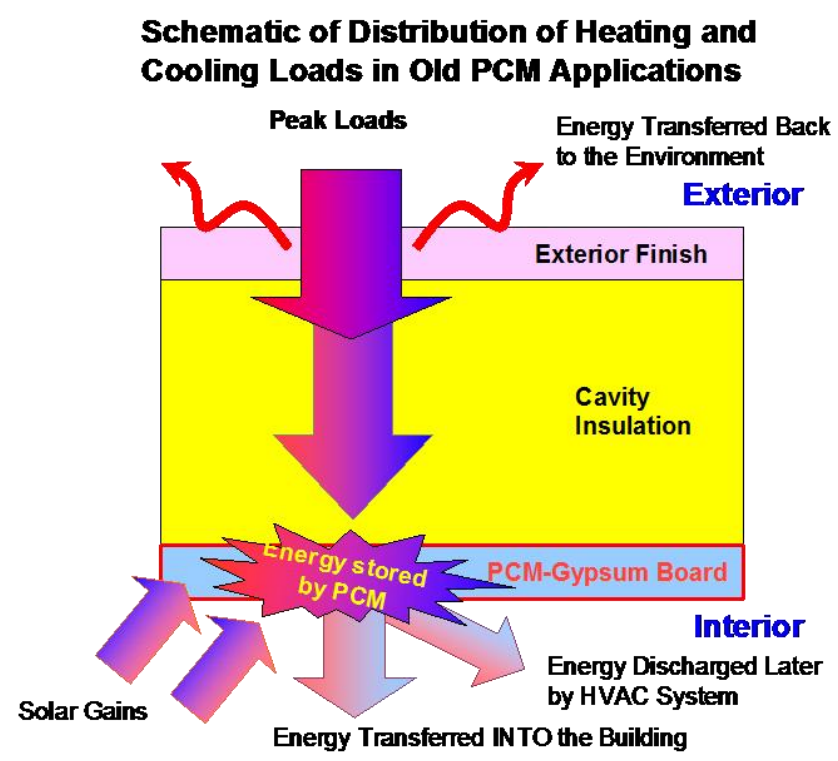

Figure 1. PCM as part of the interior surface of the building envelope.

As shown in Figure 2, the present approach takes advantage of the large temperature fluctuations that take place in residential attics or at the exterior wall surfaces. These energy fluctuations, which can be a significant part of the building cooling and heating loads, are largely absorbed by the PCM-enhanced insulation and later transferred to the environment without affecting the 
interior building energy balance. This simple change in material configuration means real energy savings.

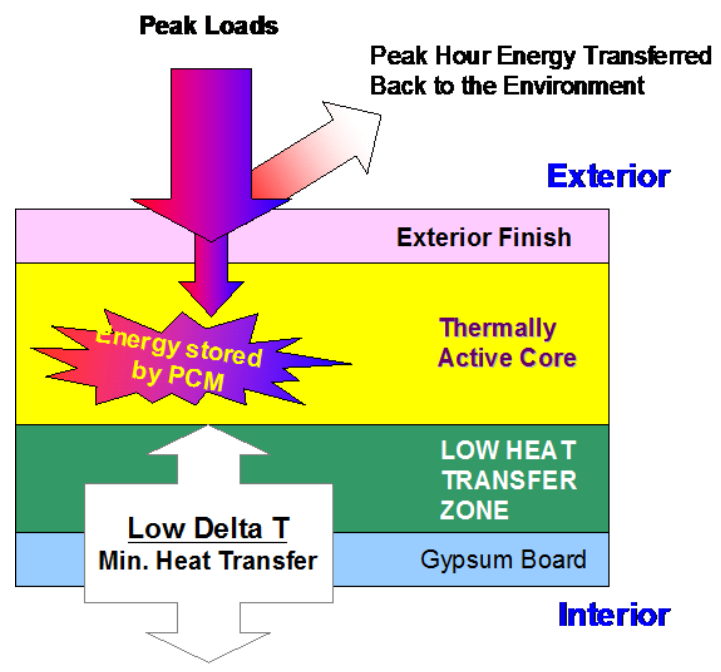

Figure 2. PCM used as an integral part of the building thermal envelope.

It is expected that this new placement method for PCM should significantly reduce flammability issues that were common in earlier technology developments. Also, detailed optimizations performed for PCM applications showed significant potential for reduction of initial costs and a corresponding reduction in payback time. In the case of PCM-enhanced cellulose, the product optimization process is focused mostly on analysis of thermal performance as a function of the PCM fusion temperature range, the minimum necessary amount of PCM storage, and an optimum PCM content in cellulose fibers. For example, hot box experiments demonstrated the potential for reducing the amount of PCM inside the wall cavity by about $50 \%$. Several additional cellulose insulation blends containing less than $20 \%$ of PCM are being considered as well. A more detailed economic analysis for PCM-enhanced insulation is presented later in this report.

In the ORNL research that is under way, microencapsulated paraffinic PCM is positioned inside the wall cavity or installed as a part of the attic insulation system. The melting temperature of the PCM is as close as possible to the set-point temperature of the building interior space. As a result, heat transfer between the wall core and the interior space is reduced.

\section{LESSONS FROM PAST PCM TESTING IN BUILDING ENVELOPES}

PCMs have been used in buildings for at least 40 years. Many potential PCMs - including inorganic salt hydrates, organic fatty acids and eutectic mixtures, fatty alcohols, neopentyl glycol, and paraffinic hydrocarbons - were tested for building applications. There were several moderately successful attempts in the1970s and 1980s to use different types of organic and inorganic PCMs to reduce peak loads and heating and cooling energy consumption (Balcomb et al. 1983). These investigations focused on impregnating concrete, gypsum, or ceramic masonry with salt hydrates or paraffinic hydrocarbons. Most of these studies found that PCMs improved 
building energy performance by reducing peak-hour cooling loads and by shifting peak-demand time.

Paraffinic hydrocarbons PCMs generally performed well, except that they compromised the flammability resistance of the building envelope. Kissock et al. (1998) reported that wallboard including a paraffin mixture made up mostly of n-octadecane, which has a mean melting temperature of $24^{\circ} \mathrm{C}\left(75^{\circ} \mathrm{F}\right)$ and a latent heat of fusion of $143 \mathrm{~kJ} / \mathrm{kg}(65 \mathrm{Btu} / \mathrm{lb})$,

was easy to handle and did not possess a waxy or slick surface. It scored and fractured in a manner similar to regular wallboard. Its unpainted color changed from white to gray. The drywall with PCM required no special surface preparation for painting.

In addition, Salyer and Sircar (1989) reported that during tests of $1.22 \times 2.44 \mathrm{~m}(4 \times 8 \mathrm{ft})$ wallboard with PCM, there was no statistically significant loss of PCM or "pooling" even after 3 months of exposure to continuously cycled $37^{\circ} \mathrm{C}\left(100^{\circ} \mathrm{F}\right)$ air.

The ability of PCMs to reduce peak loads is also well documented. For example, Zhang, Medina, and King (2005) found peak cooling load reductions of 35 to $40 \%$ in side-by-side testing of conditioned small houses with and without paraffin PCM inside the walls. Similarly, Kissock et. al. (1998) measured peak temperature reductions of up to $10^{\circ} \mathrm{C}\left(18^{\circ} \mathrm{F}\right)$ in side-by-side testing of unconditioned experimental houses with and without paraffin PCM wallboard.

Earlier ORNL research on PCM-impregnated gypsum board showed that PCM-board required a significant increase of the surface convection coefficient (up to three times) to provide proper conditions for charging and discharging of PCM. It was related due to limited temperature fluctuations available inside the building space (Stovall and Tomlinson 1995). ORNL testing and modeling of perlite granulate impregnated with inorganic PCM demonstrated a good capability for reducing temperature fluctuations compared with traditional fiberglass insulation (Petrie et al. 1997).

During 2004-2006, the ORNL team developed and tested PCM-enhanced thermal insulation that is a thermal mass component of the building envelope. Small amounts of different cellulosePCM blends were produced with the use of a pilot-scale production line (Kosny, Yarbrough, and Wilkes 2006). In this project, microencapsulated paraffinic PCM was used. The PCM microcapsules were $2-20 \mu \mathrm{m}$ in diameter and their mean melting point was $78.5^{\circ} \mathrm{F}\left(25.8^{\circ} \mathrm{C}\right)$. This PCM is produced with the use of a new microencapsulation technology in which microscopic wax droplets are contained inside hard acrylic polymer shells. Figure 3 shows calorimetric data for the PCM (Micronal) used in the ORNL experiments. The total phase change enthalpy for the PCM was $52 \mathrm{Btu} / \mathrm{lb}(121 \mathrm{~J} / \mathrm{g})$. Because the production of cellulose insulation already includes the addition of dry chemicals, the addition of a dry PCM component did not require significant changes in the manufacturing or packaging processes.

The distribution of PCM in the cellulose was observed using a scanning electron microscope (Figure 4). It was noted that for PCM amounts higher than 10\%, the PCM formed clusters of pellets between cellulose fibers. The fiber structure of the cellulose insulation was able to 
support the addition of up to $40 \%$ PCM microcapsules by weight without segregation. The authors speculate that because of better contact among individual PCM pellets, the heat transfer within the PCM clusters was less restricted, improving the overall performance of the PCM.

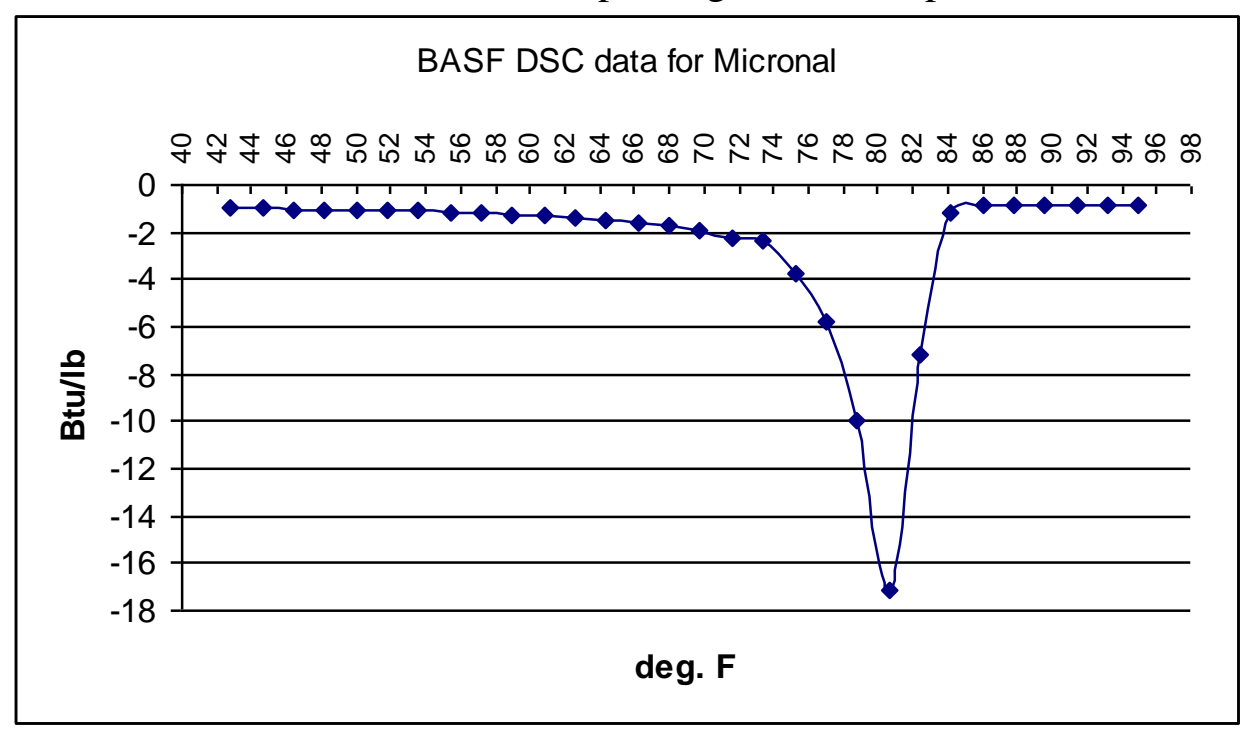

Figure 3. Calorimetric data for microencapsulated PCM used during ORNL field experiments. (Source: BASF. Used by permission.)

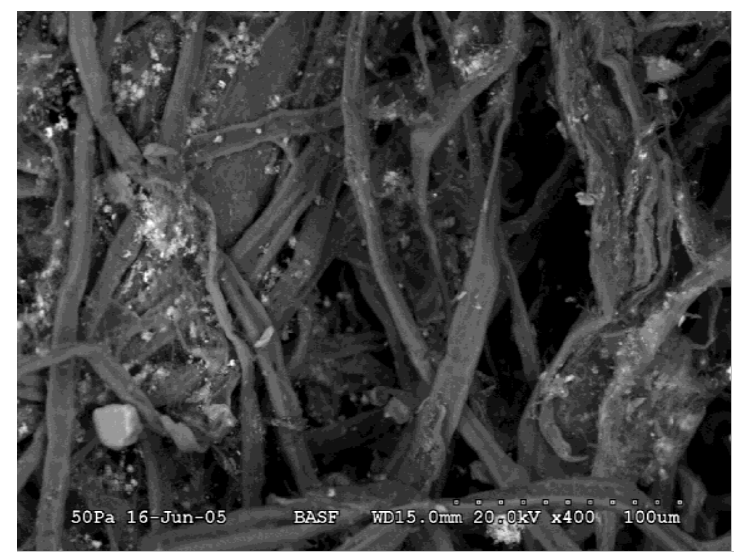

Cellulose without PCM: fire-retardant chemicals are visible.

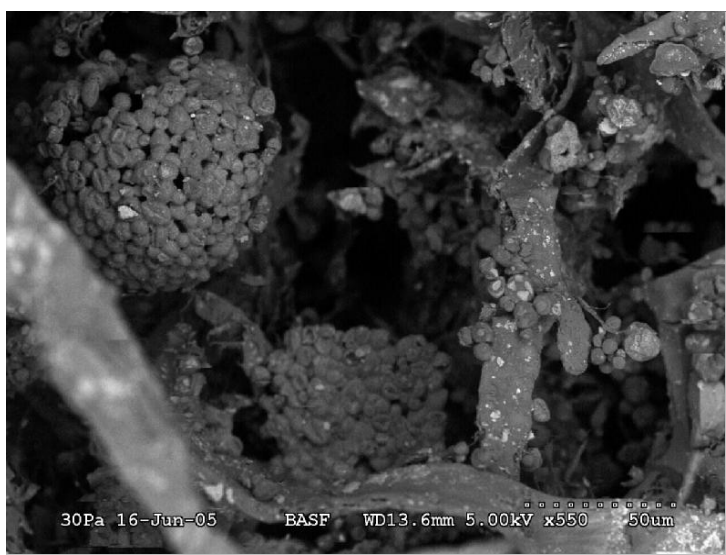

Cellulose with $30 \%$ PCM: clusters of PCM pellets are visible.

Figure 4. Scanning electron microscope images of PCM-cellulose blend.

However, in larger amounts, PCM clusters may increase the thermal conductivity of the PCMenhanced insulation. The thermal significance of the PCM clusters must be investigated more closely in the future.

A heat-flow apparatus was used to conduct a series of steady-state thermal conductivity measurements on 2 in. $(5 \mathrm{~cm}$.) thick samples of PCM-enhanced cellulose insulation. These tests showed that the addition of up to $30 \%$ of the microencapsulated PCM does not increase the thermal conductivity of the cellulose insulation (Kosny, Yarbrough, and Wilkes 2006). Figure 5 depicts hot-box test-generated heat fluxes for both parts of the wall, recorded during the rapid warm-up excitation from -70 to $110^{\circ} \mathrm{F}\left(21\right.$ to $\left.43^{\circ} \mathrm{C}\right)$. The measurements showed that for the first 
5 hours after the thermal ramp, the PCM-enhanced cellulose material reduced the total heat flow through the wall by over $40 \%$. Surface temperatures on the part of the test wall specimen containing $\mathrm{PCM}$ were approximately $2^{\circ} \mathrm{F}\left(1^{\circ} \mathrm{C}\right)$ lower during the time of the thermal ramp.

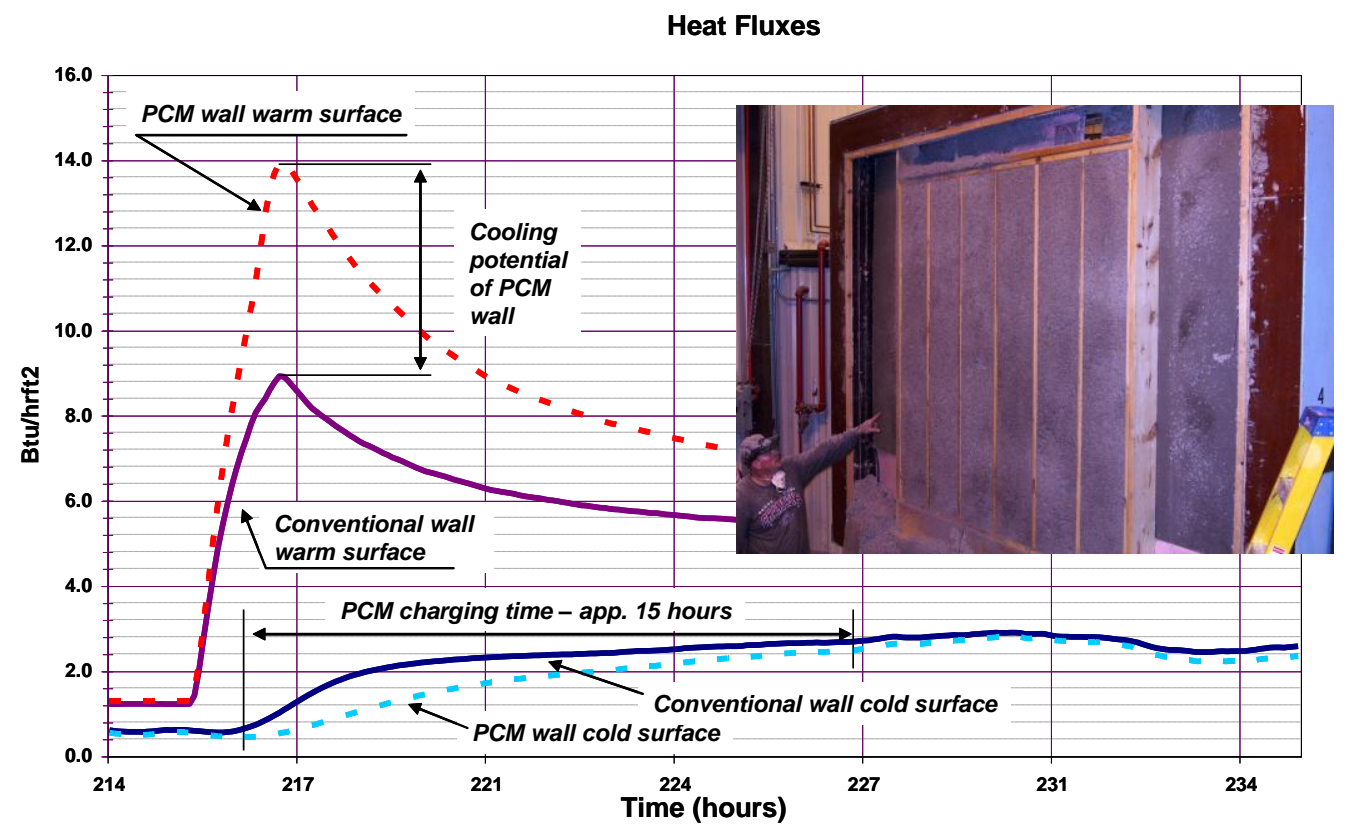

Figure 5. Heat flux measured during the dynamic hot-box experiment performed on a $2 \times 6$ wood stud wall containing PCM-enhanced cellulose insulation.

\section{FIELD TEST FACILITIES USED FOR EXPERIMENTAL EVALUATION}

During 2006, two small-scale field tests were performed on $2 \times 6(6 \times 15 \mathrm{~cm})$ wood frame walls insulated with PCM-enhanced cellulose. Test walls were installed in Oak Ridge, Tennessee, and Charleston, South Carolina. In both cases, walls containing PCM-enhanced cellulose insulation were constructed next to identical wood stud walls containing cellulose insulation with no PCM. To estimate the effect of direct solar radiation, the Oak Ridge walls faced south and the Charleston walls faced northwest.

The Oak Ridge test wall installation is presented in Figure 6. During April 2006, a $4 \times 8 \mathrm{ft}$ $(1.2 \times 2.4 \mathrm{~m})$ wood-framed wall specimen was used for the small-scale field testing. The test wall was constructed with $2 \times 6$ in. $(6 \times 15.2 \mathrm{~cm})$ wood framing installed 16 in. o.c. $(41 \mathrm{~cm})$. Three wall cavities were insulated with conventional cellulose with a density of about $2.6 \mathrm{lb} / \mathrm{ft}^{3}\left(42 \mathrm{~kg} / \mathrm{m}^{3}\right)$. The approximate R-value of the cavity insulation was R-20 h. $\mathrm{ft}^{2} \cdot{ }^{\circ} \mathrm{F} / \mathrm{Btu}\left(3.52 \mathrm{~m}^{2} \cdot \mathrm{K} / \mathrm{W}\right)$. Three wall cavities of the same size were insulated with a cellulose-PCM blend with a density of about $2.6 \mathrm{lb} / \mathrm{ft}^{3}\left(42 \mathrm{~kg} / \mathrm{m}^{3}\right)$ and containing about $22 \%$ by weight of PCM. Microencapsulated paraffinic PCM was used in this test. The PCM microcapsules were 2-20 $\mu \mathrm{m}$ in diameter, and their melting point was $78.5^{\circ} \mathrm{F}\left(26^{\circ} \mathrm{C}\right)$. It is estimated that about $20 \mathrm{lb}(9 \mathrm{~kg})$ of PCM-enhanced cellulose insulation containing $4.5 \mathrm{lb}(2 \mathrm{~kg}$ ) of PCM was used for this dynamic experiment. During the Oak Ridge PCM experiment, the air temperature inside the test building was kept at $78^{\circ} \mathrm{F}\left(26^{\circ} \mathrm{C}\right)$, the melting point of the PCM. The air temperature inside the Oak Ridge test building was intentionally set relatively high, at the melting point temperature of the PCM, to reduce 
undesirable heat transfer. The fusion temperatures of paraffinic PCMs can be adjusted relatively easy during the production process. In real-life situations, the room temperature would

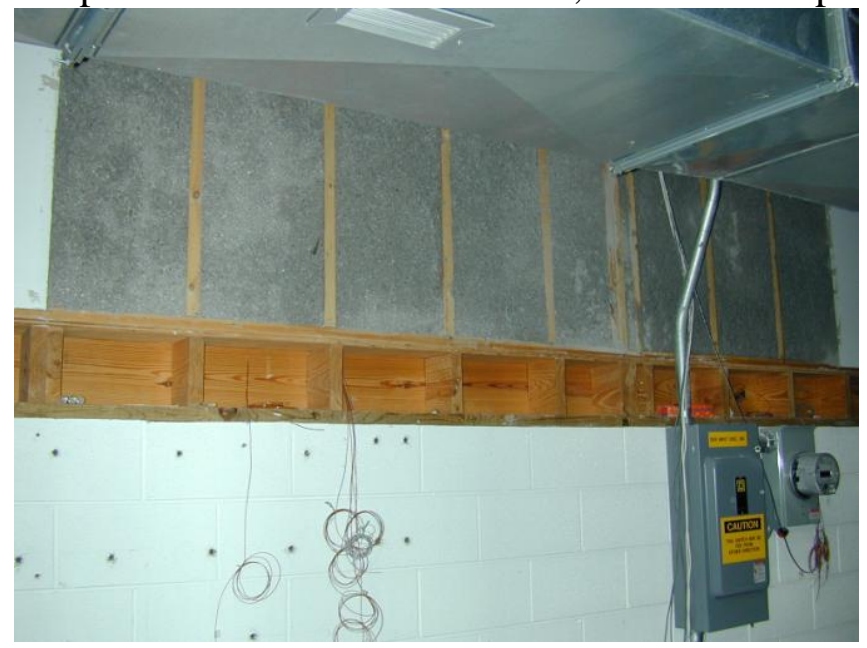

Figure 6. ORNL test wall containing PCM-enhanced cellulose insulation.

be set at the thermal comfort level, and the melting point of the PCM would be tailored to match this temperature. Different temperatures are possible depending upon whether the cooling or heating loads are more important for a particular location.

In May and June 2006, in the Charleston testing facility (Figure 7), two wood stud walls were used for testing. The total size of the test wall was $8 \times 8 \mathrm{ft}(2.4 \times 2.4 \mathrm{~m})$. These walls were constructed with $2 \times 6-$ in. $(6 \times 15.2 \mathrm{~cm})$ wood framing installed 24 -in. o.c. $(61 \mathrm{~cm})$. One part of the wall was insulated with conventional cellulose with a density of about $2.6 \mathrm{lb} / \mathrm{ft}^{3}\left(42 \mathrm{~kg} / \mathrm{m}^{3}\right)$. Two other wall cavities were insulated with a cellulose-PCM blend with a density of about $2.6 \mathrm{lb} / \mathrm{ft}^{3}$ $\left(42 \mathrm{~kg} / \mathrm{m}^{3}\right)$ and containing about $22 \% \mathrm{PCM}$ by weight. It is estimated that about $38 \mathrm{lb}(17 \mathrm{~kg})$ of PCM-enhanced cellulose insulation containing $8 \mathrm{lb}(3.6 \mathrm{~kg})$ of PCM was used for this dynamic experiment. The air temperature inside the Charleston building was kept at about $69^{\circ} \mathrm{F}\left(20^{\circ} \mathrm{C}\right)$ about $10^{\circ}$ below the level of the theoretical melting point of PCM.

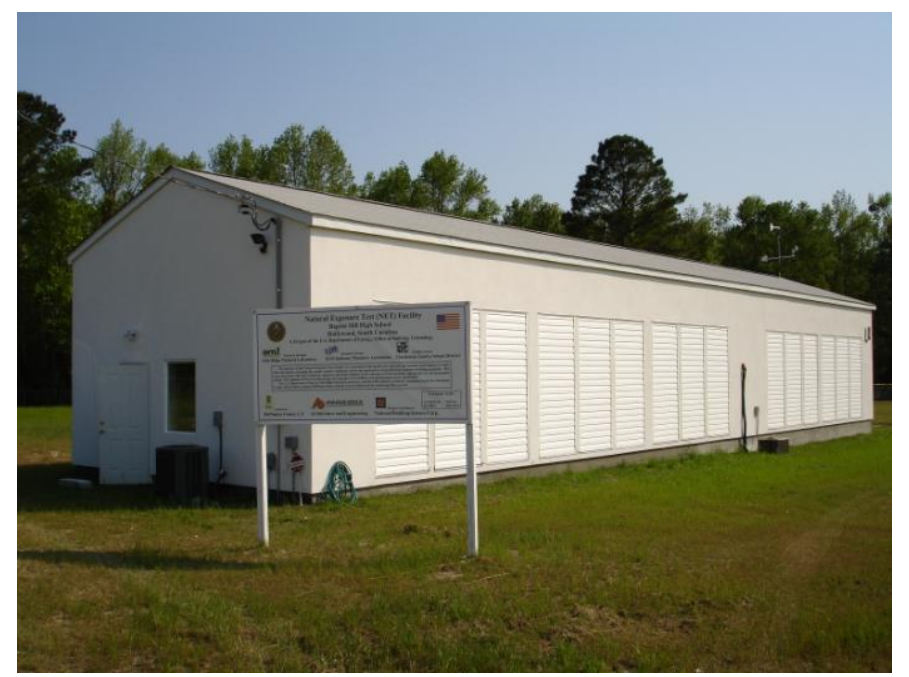


Figure 7. Charleston testing facility.

As shown in Figure 8, the test walls installed in Charleston were slightly different from those tested in Oak Ridge - the wall cavities were 24 in. $(61 \mathrm{~cm}$ o.c.). The greater width of the wall cavities caused problems with the dry installation of the cellulose. The PCM microcapsules behaved like a lubricant and broke the fiber structure of the cellulose, causing the insulation to fall out of the wall cavity. Therefore, a second installation was necessary that used a supporting fiber mesh.

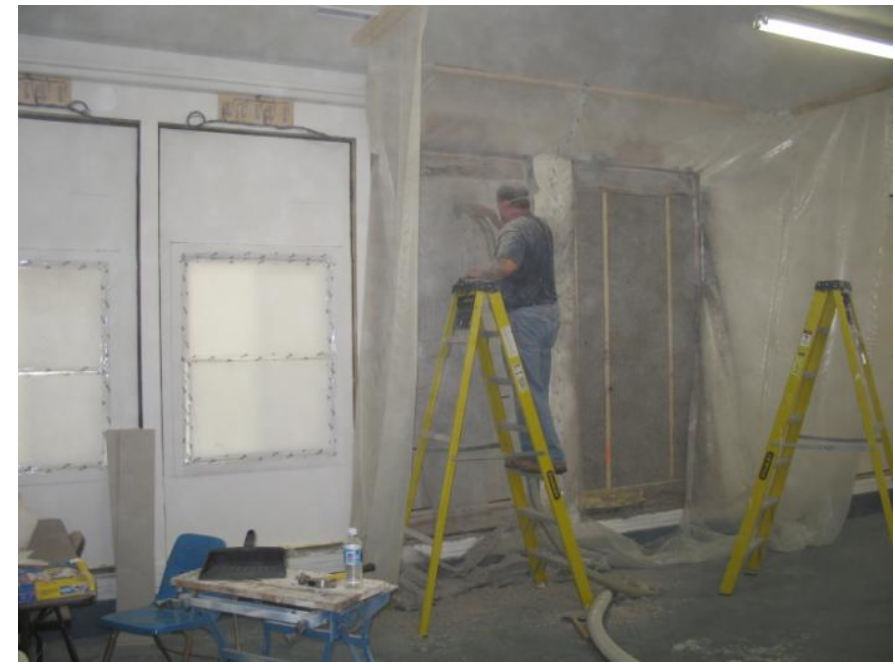

Figure 8. Installation of cellulose insulation in the Charleston Testing Facility.

\section{SUMMARY OF THE OAK RIDGE FIELD TEST RESULTS}

\section{Exterior Thermal Excitations}

The Oak Ridge field measurements started in April 2006. This report presents a summary of results for a 38-week time period ending in December 2006. Wall surfaces were instrumented with heat flux transducers to monitor surface heat flows. Thermocouple arrays were installed (at 1 in. intervals) through the wall cavities to monitor temperature profiles inside the wall. Exterior weather conditions (solar irradiation and temperatures) were monitored by a weather station.

Solar measurements for the test wall showed relatively stable weekly values in the period between April and September 2006. As depicted in Figure 9, summer average values of the solar radiation incident on a vertical south-facing surface oscillated from 600 to $700 \mathrm{Btu} / \mathrm{ft}^{2}$ (1890 to $2205 \mathrm{~W} / \mathrm{m}^{2}$ ) per day. Solar irradiation was the highest during September and October, reaching $1200 \mathrm{Btu} / \mathrm{ft}^{2}\left(3780 \mathrm{~W} / \mathrm{m}^{2}\right)$ per day.

Temperature measurements for the ambient air are presented in Figure 10. In addition, maximum, minimum, and average temperatures were recorded for each day. Mean temperatures (TA) computed from maximum and minimum temperatures were recorded for each day as well. The average difference between maximum and minimum temperatures recorded during the Oak 
Ridge experiment was $33^{\circ} \mathrm{F}\left(18^{\circ} \mathrm{C}\right)$. The average temperature was usually about $16^{\circ} \mathrm{F}\left(9^{\circ} \mathrm{C}\right)$ degrees higher than the daily minimum. During the summer months, maximum daily

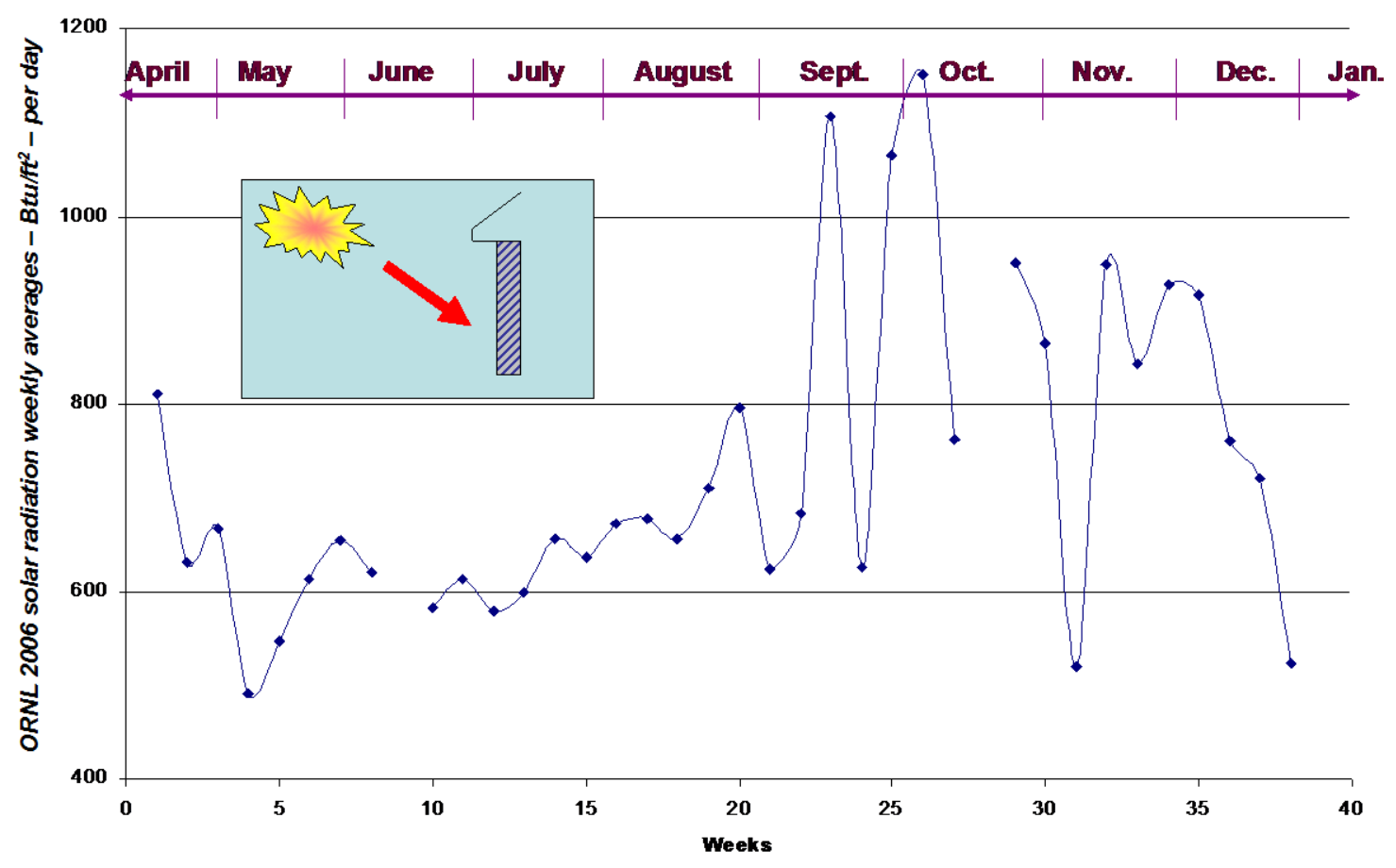

Figure 9. Measured solar radiation on the south-facing wall of the ORNL test facility.

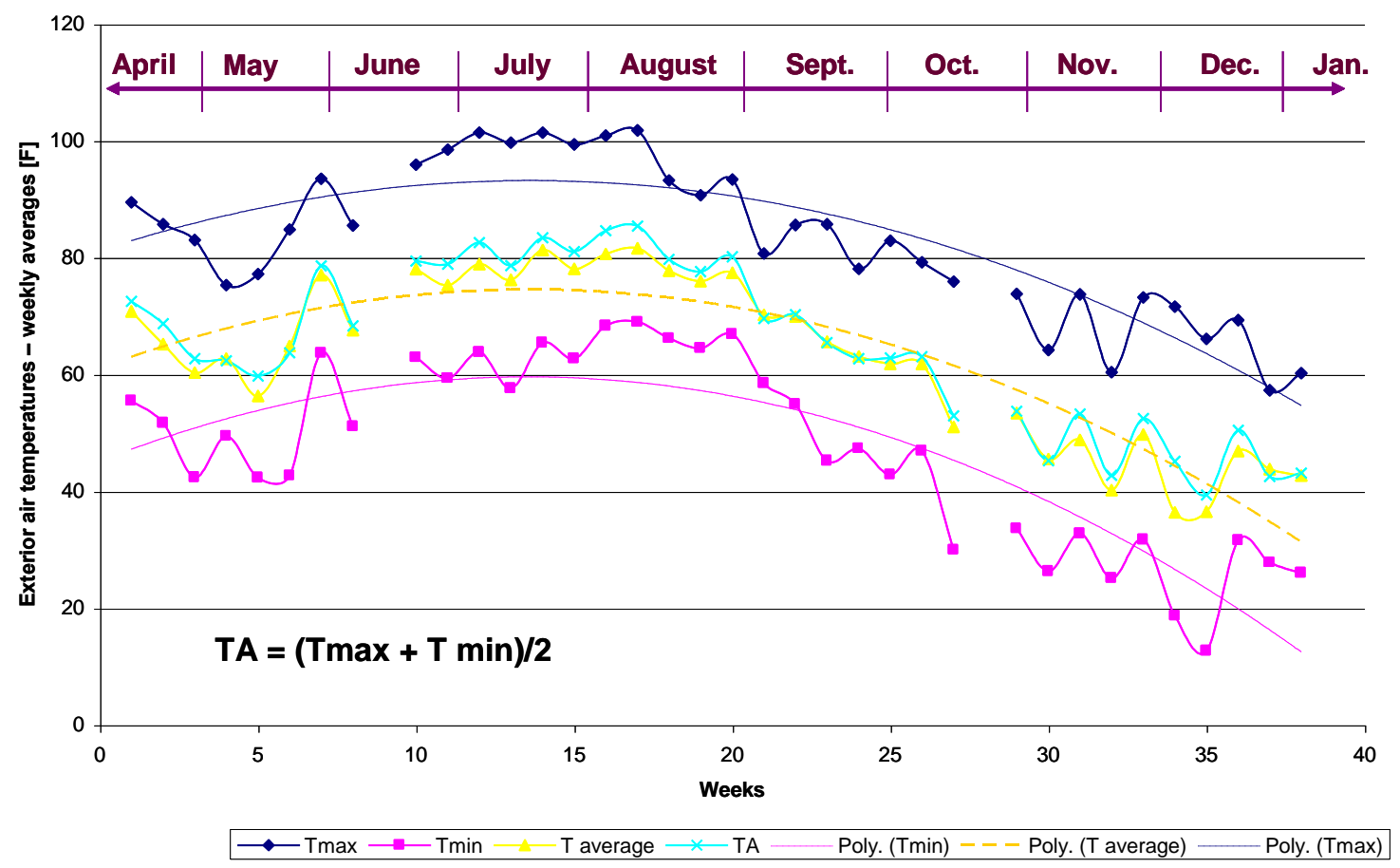

Figure 10. Ambient air temperatures recorded during the ORNL PCM field experiment. 
temperatures exceeded $100^{\circ} \mathrm{F}\left(38^{\circ} \mathrm{C}\right)$; at the same time, minimum daily temperatures were 60 $75^{\circ} \mathrm{F}\left(16-22^{\circ} \mathrm{C}\right)$. During December (the coldest month), minimum temperatures oscillated between 15 and $35^{\circ} \mathrm{F}\left(-10\right.$ and $\left.+2^{\circ} \mathrm{C}\right)$.

Exterior surface temperatures for both walls were close, usually varying by no more than $2^{\circ} \mathrm{F}$ $\left(1^{\circ} \mathrm{C}\right)$. As shown in Figure 11, for the wall containing PCM, maximum wall surface temperatures were relatively high, staying between 100 and $130^{\circ} \mathrm{F}\left(38\right.$ and $\left.54^{\circ} \mathrm{C}\right)$ for the late spring-early summer time period (between April and mid-July). In the following months, these temperatures oscillated between 120 and $145^{\circ} \mathrm{F}\left(49\right.$ and $\left.63^{\circ} \mathrm{C}\right)$. It was surprising that even in December, maximum wall surface temperatures were over $120^{\circ} \mathrm{F}\left(49^{\circ} \mathrm{C}\right)$ during sunny days. This fact suggests great potential for achieving heating energy savings by controlling the heat flux in the south-facing walls containing PCM.

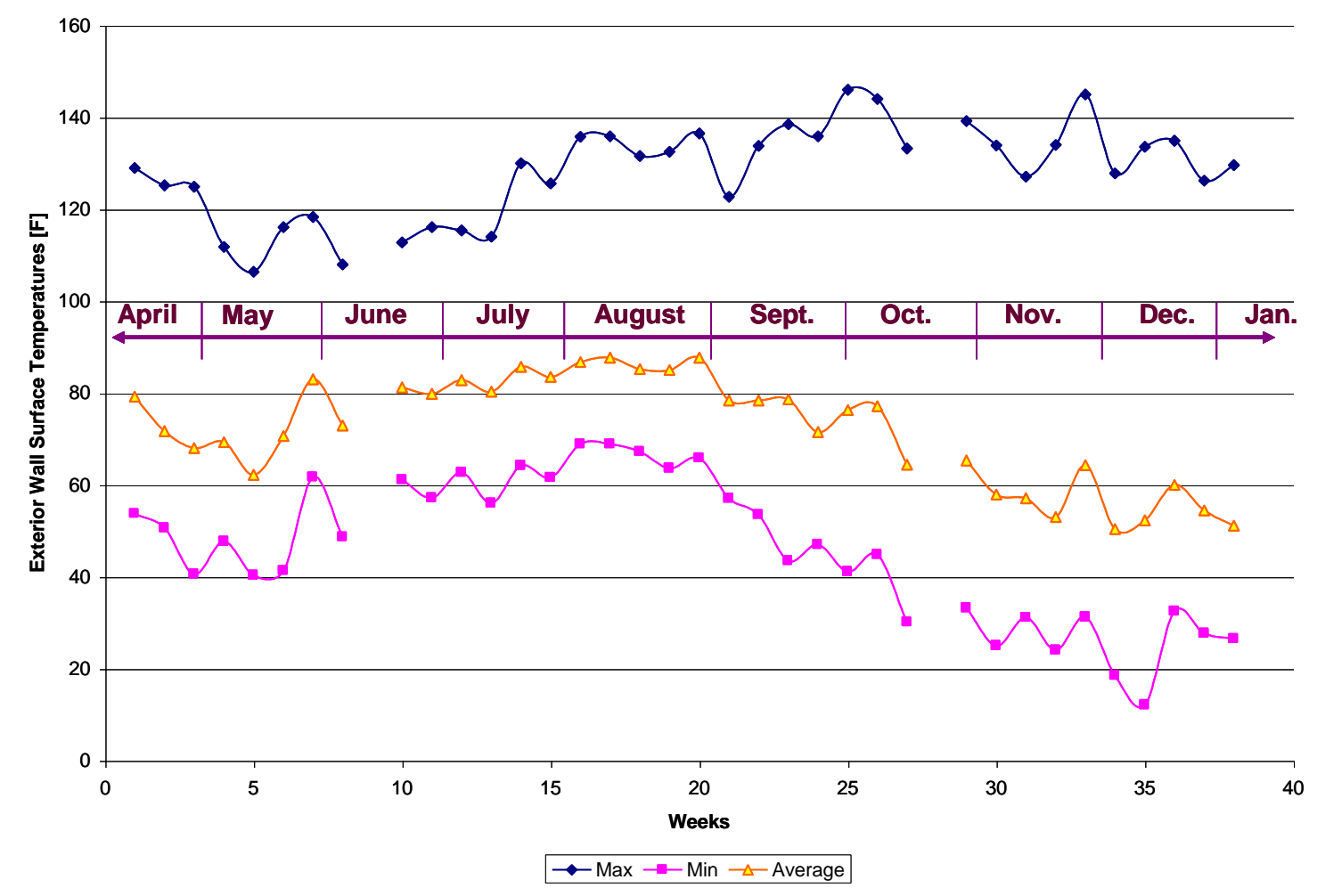

Figure 11. Exterior wall surface temperatures measured during the ORNL PCM field experiment.

As shown in Figure 12, minimum temperatures for the exterior wall surface and the ambient air were very close. The average wall surface temperature followed a trend very similar to that of the maximum ambient air temperature. Average wall surface temperatures were about 10 to $20^{\circ} \mathrm{F}$ $\left(5.5\right.$ to $11^{\circ} \mathrm{C}$ ) lower than the maximum ambient air temperatures. These facts may by useful in the future design of walls containing PCMs. 


\section{Internal Wall Temperature Profiles}

The internal cavities in the experimental walls were instrumented with an array of thermocouples to measure temperature profiles during transient thermal processes (Figure 13). To keep the exact distances between thermocouples, they were attached to the strings going across the wall



Figure 12. Comparison of ambient air temperatures and exterior wall surface temperatures recorded during the ORNL PCM field experiment. 


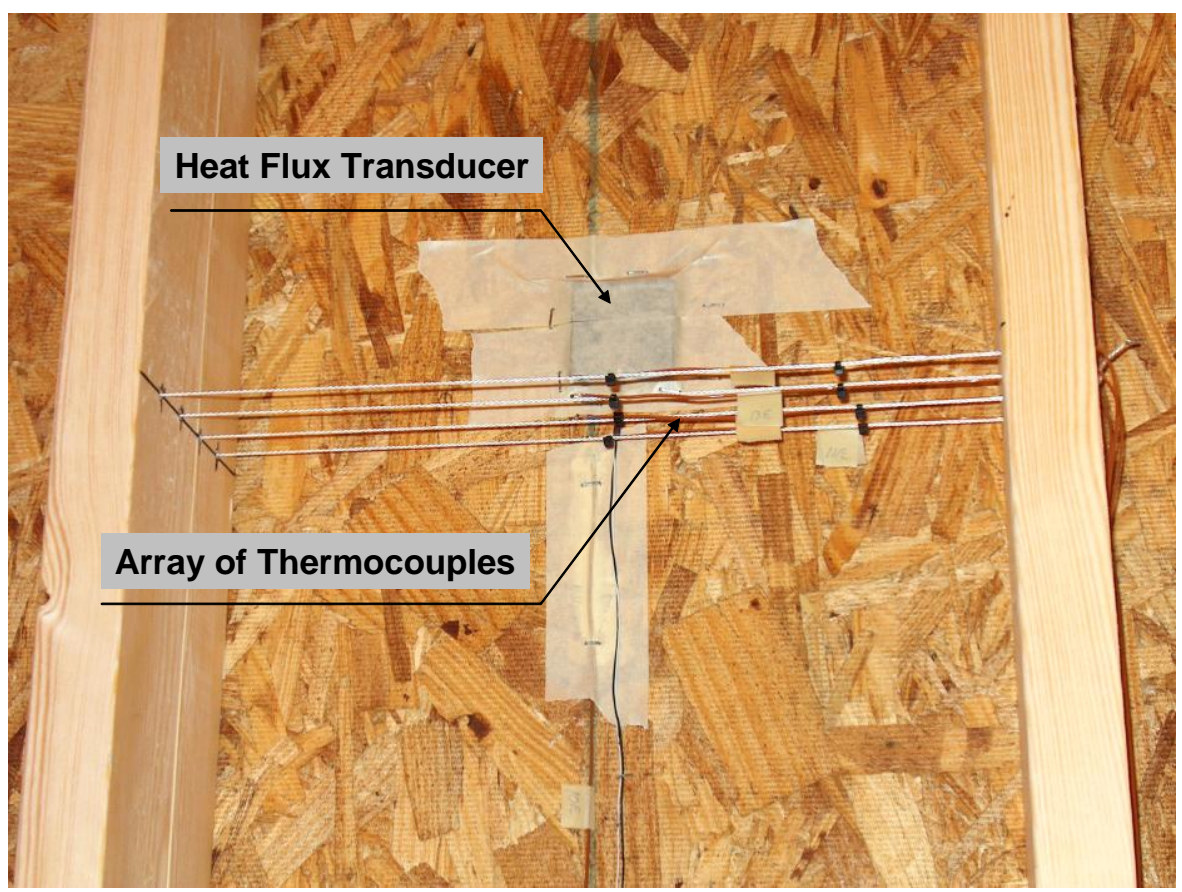

Figure 13. Instrumentation of the test walls.

cavity. Analysis of the temperature profiles was necessary to evaluate how effectively the PCM worked during the various temperature swings. As shown in Figure 13, heat flows on both of the walls' surfaces were measured using heat flux transducers located on the internal surfaces of the wall sheathing materials (facing the wall cavity for greater accuracy).

During the 2006 Oak Ridge PCM field experiment, special attention was given to determining how much of the PCM was going through the phase-change process during the daily dynamic thermal excitations. Previous dynamic hot-box tests in 2005-2006 indicated that at the maximum temperature during the thermal ramp, close to $110^{\circ} \mathrm{F}\left(43^{\circ} \mathrm{C}\right)$, in the $2 \times 6$ wood stud wall insulated with PCM-enhanced cellulose, about $40-50 \%$ of the PCM did not go through the phase-change process. The results of the field study confirmed this finding for a single-day scenario.

During a series of hot days and nights, when the PCM has little opportunity to discharge its stored energy (because the ambient temperature is too high during the night), this extra storage capacity can be very helpful. After being fully charged, the exterior part of the wall would have a temperature beyond the melting point, forcing the interior part of the wall cavity to go through the melting process. To fully understand this advantage of "extra" PCM, more work has to be done on analyzing short-term weather patterns in different climates.

Figure 14 shows temperature profiles for a series of hot days and relatively cool nights, optimum conditions for PCM to work effectively (full charging and discharging). On this chart, temperature profiles for the PCM wall are marked with solid lines and profiles for the walls containing no PCM with broken lines. Cavity locations indicate the distance from the exterior sheathing board. Significant differences in temperature profile can be observed for the same 
cavity locations in the two tested walls. It is notable that temperature fluctuations for similar cavity locations are different for the walls containing PCM or no PCM. The PCM microcapsules were thermally stabilizing the core of the wall by their capacity to store heat.

For a closer analysis of the phase change processes, Figure 15 presents interior wall cavity temperatures for two different days (taken from two different weeks). It can be observed that the melting process for the $\mathrm{PCM}$ started at about $78^{\circ} \mathrm{F}\left(25.5^{\circ} \mathrm{C}\right)$ and ended at about $82^{\circ} \mathrm{F}\left(28^{\circ} \mathrm{C}\right)$. The temperature range for the PCM solidifying process was between 81 and $83^{\circ} \mathrm{F}\left(27\right.$ and $\left.28^{\circ} \mathrm{C}\right)$.

For 38 weeks of the field tests reported, analysis of the temperature profiles in the tested walls showed that the PCM was going through full charging and discharging processes during the 24hour time periods. Examples of the recorded temperature profiles, presented in Figures 14 and 15 , demonstrate clearly that the heat storage capacity of the PCM thermally stabilized the core of the wall. Temperature peaks shifted notably inside the PCM wall. Significantly lower temperatures were observed during the nighttime in the wall cavities where no PCM was used. A conventional wall (with no PCM) was warming up and cooling down significantly faster than the wall containing PCM. The reason is that by addition of PCM, heat capacitance of the cellulose insulation was increased from about $2 \mathrm{Btu}$ or $2.1 \mathrm{KJ}$ per $\mathrm{ft}^{2}$ of the wall area to $14.6 \mathrm{Btu}$ and 15.4 $\mathrm{KJ}$ (for temperature band $10{ }^{\circ} \mathrm{F}, 5^{\circ} \mathrm{C}$, as shown on Fig. 14 for the center of cavity- blue line).

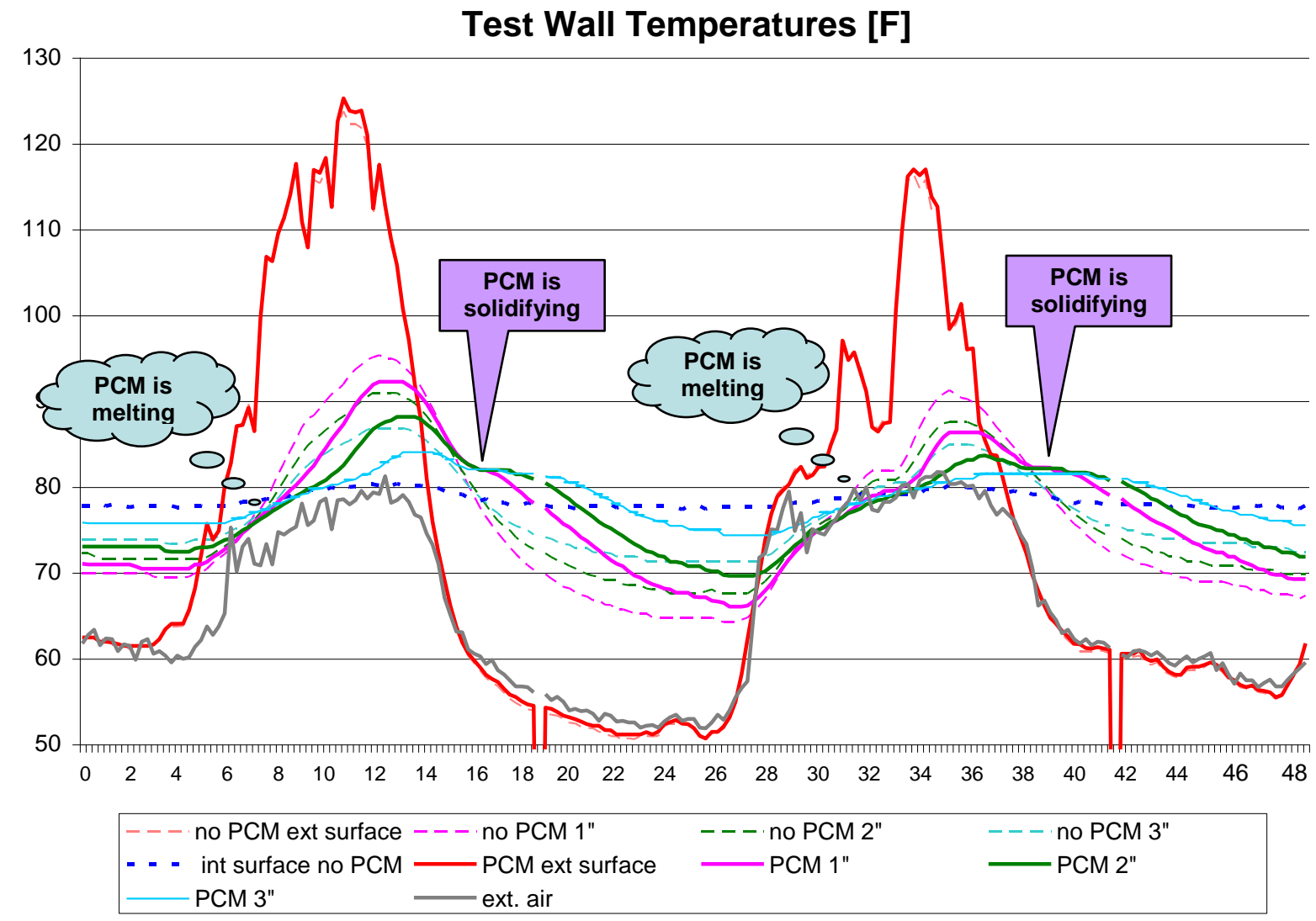

Figure 14. Comparison of temperatures recorded inside the cavities of tested walls. 


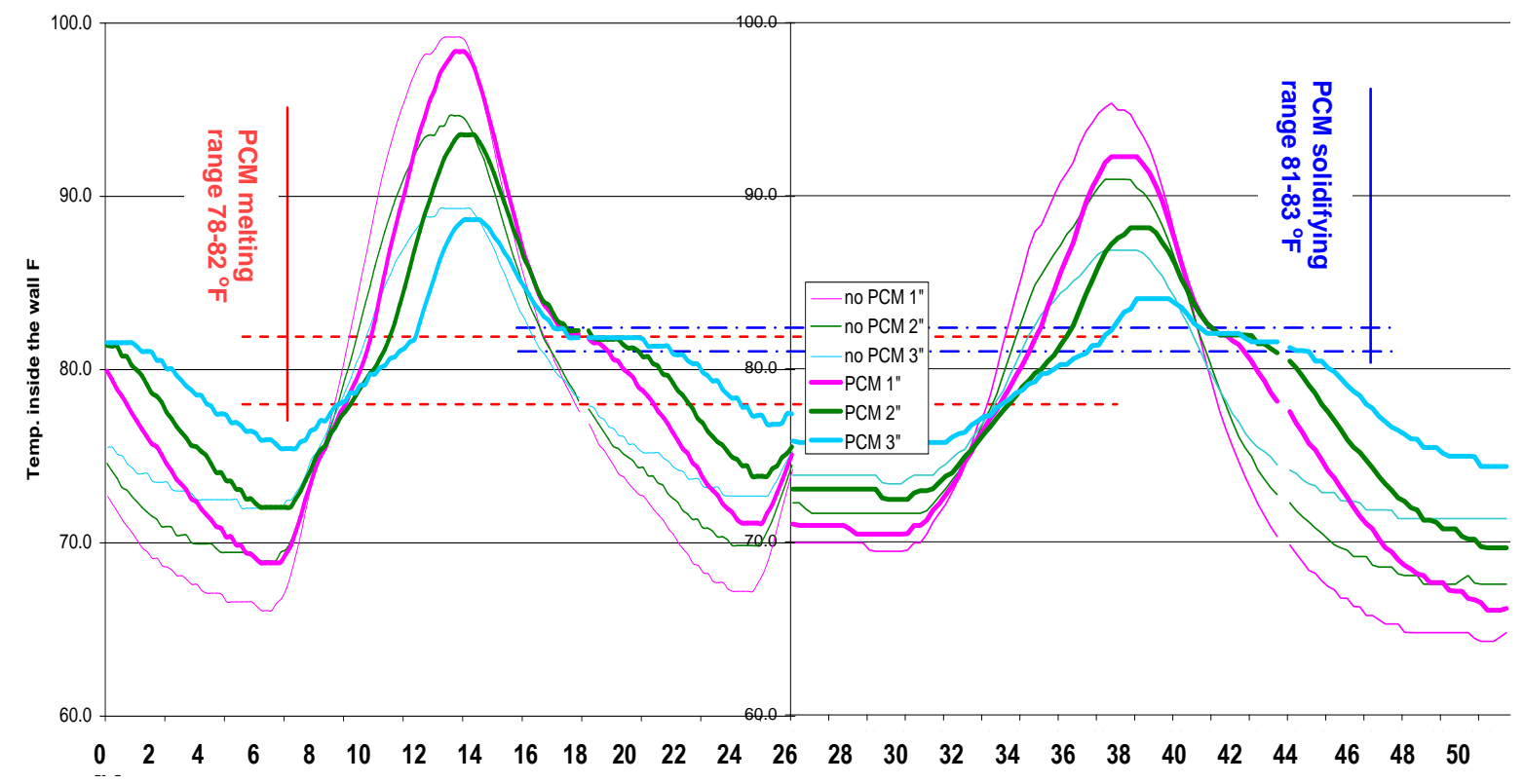

Figure 15. Comparison of PCM melting and freezing temperatures recorded on two different days.

\section{Recorded Heat Flows}

As shown in Figure 13, internal cavities in the experimental walls were instrumented with arrays of thermocouples and heat flux transducers. Heat flows on the surfaces of both walls were measured using heat flux transducers located on the internal surfaces of the wall sheathing materials. Figure 16 shows internal surface heat fluxes recorded in Oak Ridge on test walls during the sunny week of late April 2006. Negative heat fluxes represent wall cooling loads. Exterior surface temperatures on the Oak Ridge walls cycled between $120^{\circ} \mathrm{F}\left(49^{\circ} \mathrm{C}\right)$ during the day and $55^{\circ} \mathrm{F}\left(12.7^{\circ} \mathrm{C}\right)$ during most nights. Field test data demonstrated that the wall containing PCM was more thermally stable than the conventional wall containing no PCM. Significantly lower heat fluxes were observed in the PCM wall. During that week, negative (internal) heat flow (or cooling load) was reduced by $60 \%$ on average compared with the conventional wall without PCM. In addition, a shift of the peak-hour load by about 2 hours was observed in the PCM wall. It is good to realize that spring/fall peak loads are usually of less value than summer peak loads. 


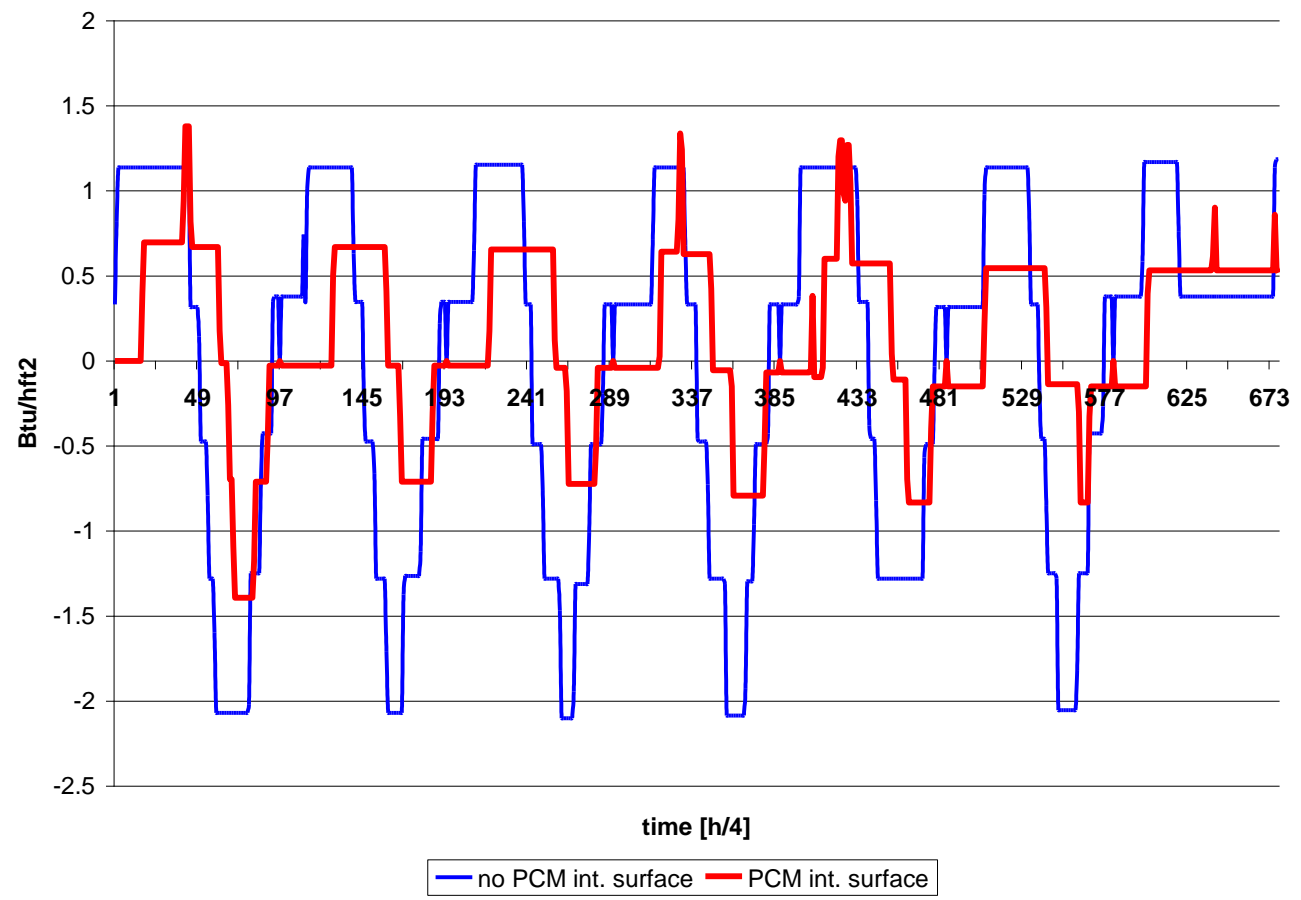

Figure 16. Comparison of interior wall surface heat fluxes recorded during the ORNL field experiment that took place during a sunny week of April 2006.

A similar heat flux chart was created for the third week of December 2006. The main objective of interest, at that time, was reduction of the positive (external) heat flow (or heating load). Figure 17 depicts heat fluxes recorded in Oak Ridge on test walls during the sunny week of December 2006 (five sunny days, cold nights). Exterior surface temperatures on the Oak Ridge walls cycled between $130^{\circ} \mathrm{F}\left(54^{\circ} \mathrm{C}\right)$ during the days and $35^{\circ} \mathrm{F}\left(2^{\circ} \mathrm{C}\right)$ during the nights. The maximum ambient air temperature during that week was, for one day, about $70^{\circ} \mathrm{F}\left(21^{\circ} \mathrm{C}\right)$. Minimum ambient air temperatures were about $35^{\circ} \mathrm{F}\left(2^{\circ} \mathrm{C}\right)$. During that week, in the wall containing PCM, a positive heat flow (heating load due to energy losses through the wall) was reduced on average by $15 \%$ compared with the conventional wall without PCM. 


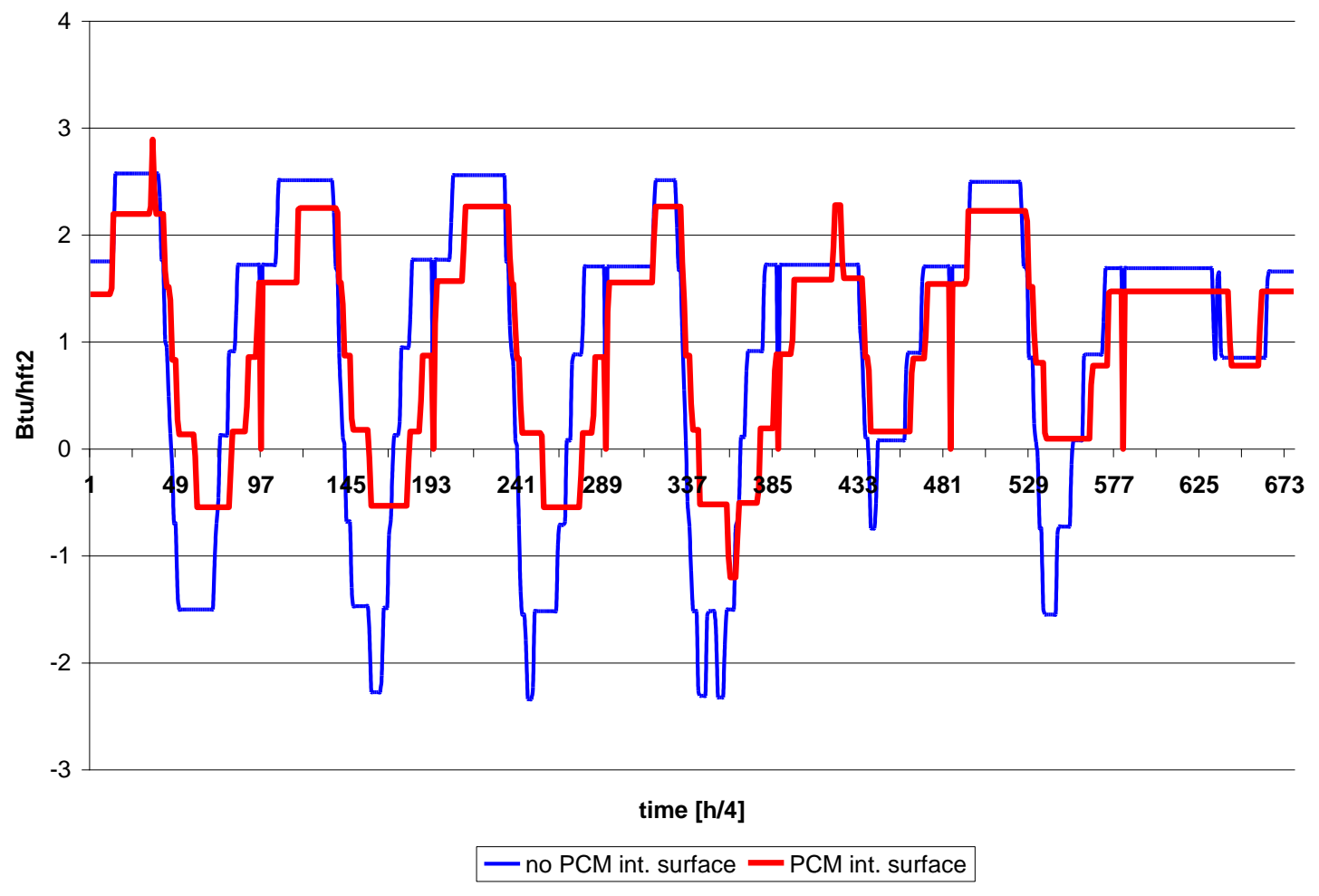

Figure 17. Comparison of interior wall surface heat fluxes recorded during the sunny week of December 2006.

For comparison, a similar heat flux chart was created for a less sunny and colder break-week between December 2006 and January 2007. Figure 18 depicts heat fluxes recorded in Oak Ridge on test walls during that week (two sunny days and one partly sunny day). Exterior surface temperatures on the Oak Ridge walls cycled between $125^{\circ} \mathrm{F}\left(52^{\circ} \mathrm{C}\right)$ during the sunny day and $25^{\circ} \mathrm{F}\left(-4^{\circ} \mathrm{C}\right)$ during the coldest nights. Maximum ambient air temperatures during that week were about $60^{\circ} \mathrm{F}\left(15^{\circ} \mathrm{C}\right)$. Minimum ambient air temperatures were between 25 and $35^{\circ} \mathrm{F}\left(-4\right.$ and $\left.2^{\circ} \mathrm{C}\right)$. During that week, a positive heat flow (heating load due to energy losses through the wall) was reduced by $4 \%$ compared with the conventional wall without PCM.

For each week analyzed during the 2006 field testing at ORNL, positive (external) and negative (internal) heat flows (representing heating and cooling loads, respectively) were integrated and compared in both tested walls. Based on the analysis of a dominant direction of the heat flow in the wall, the total 38-week-long testing time period was divided into two phases: coolingdominated time (mid-May till the second week of October) and mixed and heating-dominated time (the second half of October till the end of the year). As shown in Figure 19, for the coolingdominated time period, the average reduction of the wall-generated cooling load was about $42 \%$. 


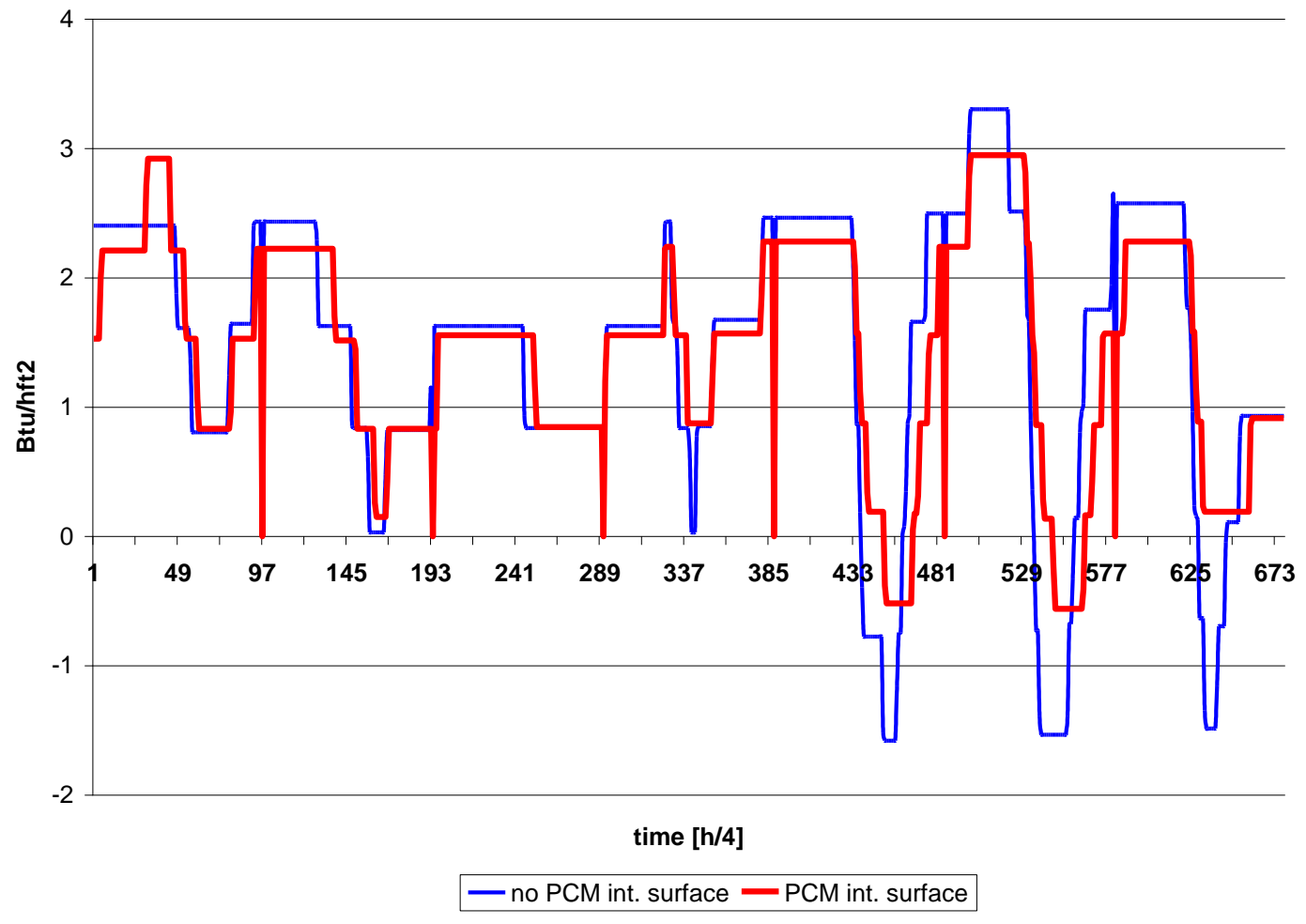

Figure 18. Surface heat fluxes recorded during the break week between 2006 and 2007.

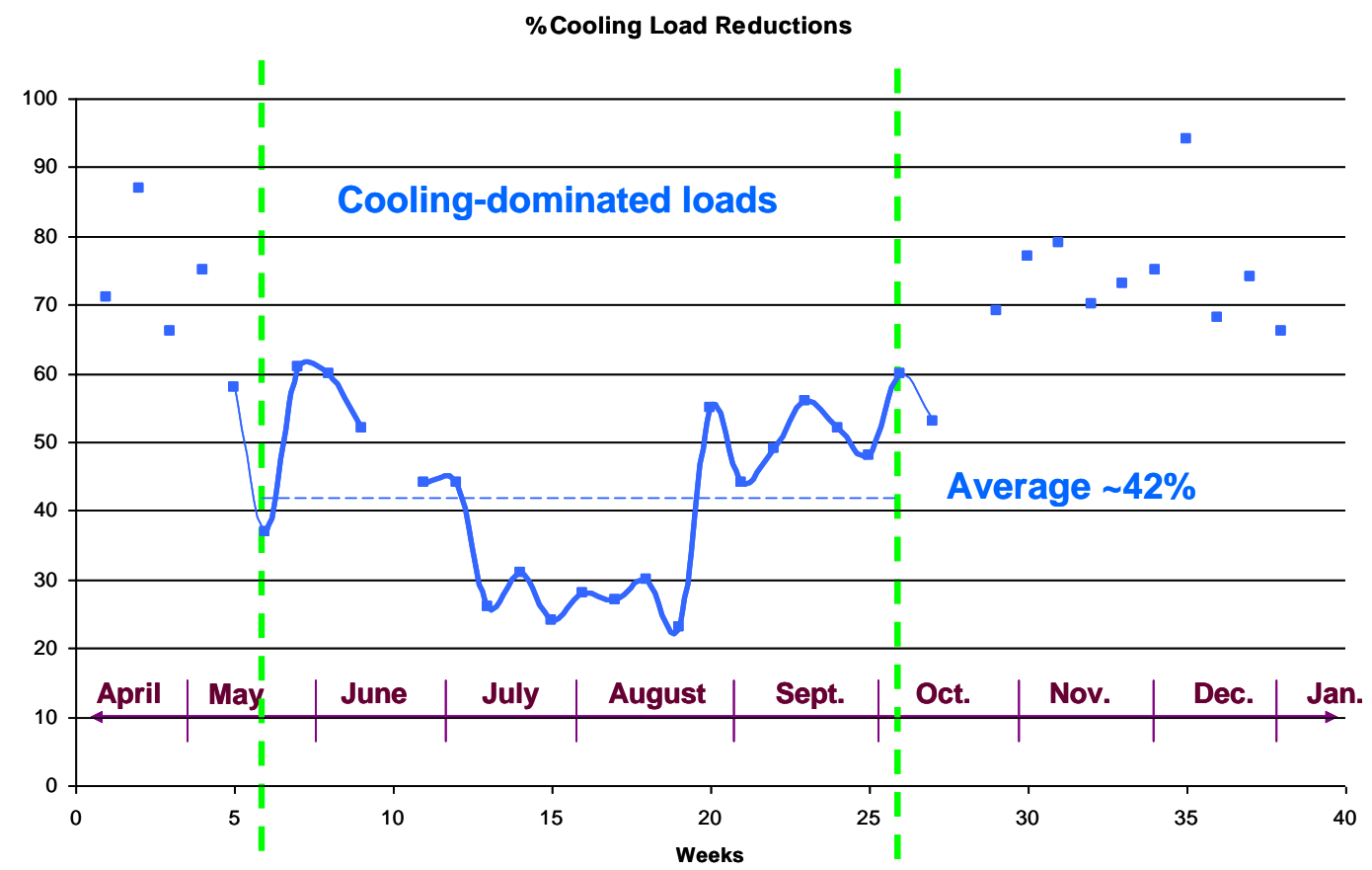

Figure 19. Weekly cooling load reductions recorded during the ORNL field experiment for the PCM wall. 
The time period between the second part of October and the end of the year was dominated by heating loads. As depicted in Figures 9 and 11, because of relatively strong solar irradiation, the maximum daily surface temperatures of the south-facing test walls oscillated between 120 and $145^{\circ} \mathrm{F}\left(49\right.$ and $63^{\circ} \mathrm{C}$ ). Even in December, which was the coldest month of the experiment, maximum wall surface temperatures were over $120^{\circ} \mathrm{F}\left(49^{\circ} \mathrm{C}\right)$ during sunny days. As shown in Figure 20, the tested configuration of the PCM wall can use this energy to reduce heating loads. For the time period between the second week of October and the end of the year, the average reduction of the heating load was about $16 \%$.

To improve performance during the heating season, a different PCM with a lower melting point probably should be used. However, reductions in the wall-generated heating loads suggest great potential for achieving heating energy savings by using PCM walls in mixed climates. More work in this area is necessary to confirm these findings.

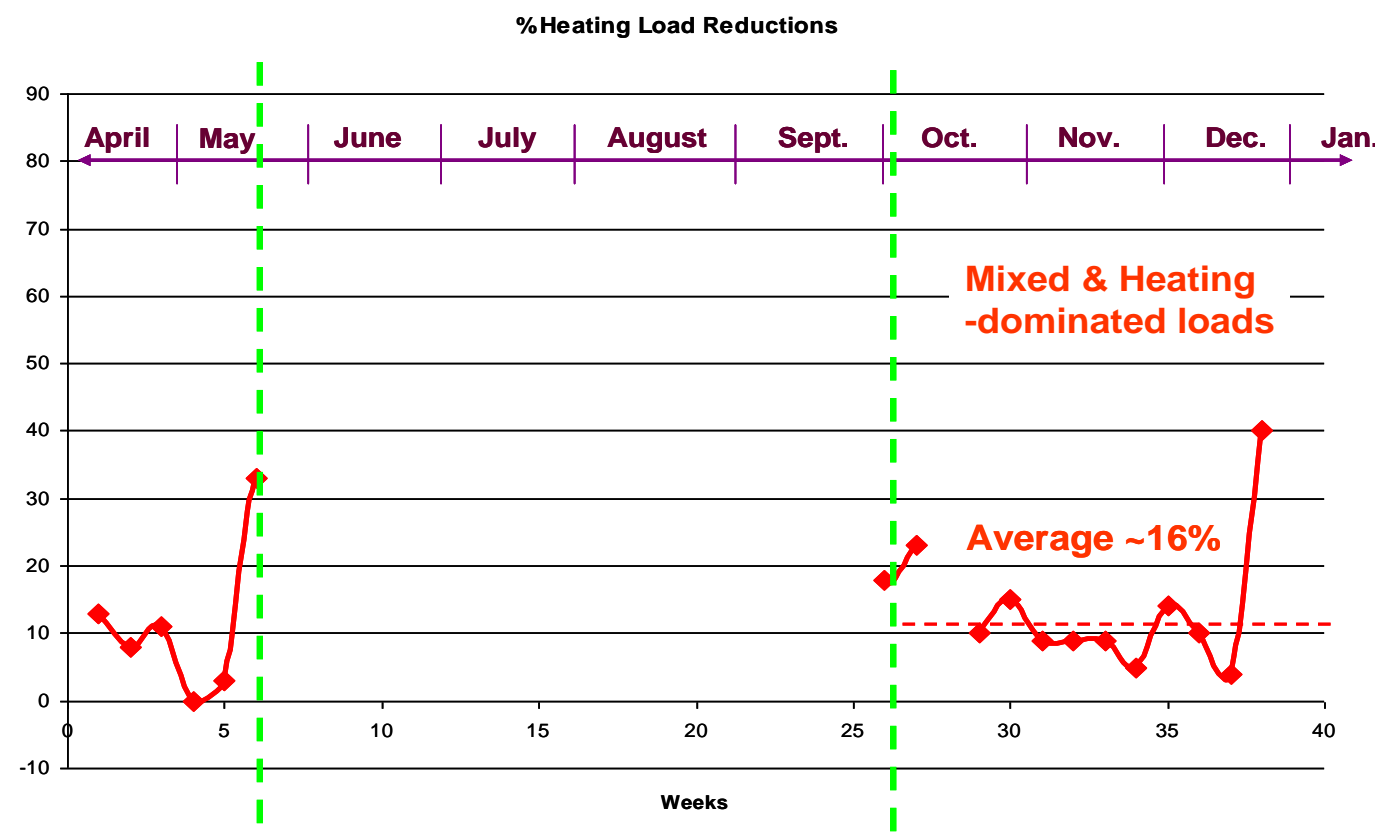

Figure 20. Weekly heating load reductions recorded during the ORNL field experiment for the PCM wall.

\section{SUMMARY OF THE CHARLESTON, SOUTH CAROLINA, FIELD TEST RESULTS}

\section{Exterior Thermal Excitations}

Charleston field measurements started in June 2006. This part of the report presents a summary of results from 31 weeks, which were recorded between June and the end of December 2006. In both walls, interior surfaces were instrumented with heat flux transducers to monitor surface heat flows precisely. The temperatures of both wall surfaces and the centers of the wall cavities were monitored. Exterior weather conditions (solar irradiation and temperature) were monitored by a small weather station. 
Solar measurements for the test wall showed relatively stable weekly values during the period between June and July 2006 and declining irradiation during the following months. As depicted in Figure 21, summer average values of the solar radiation incident on the vertical northwestfacing surface oscillated between 800 and $1300 \mathrm{Btu} / \mathrm{ft}^{2}\left(2520\right.$ and $\left.4095 \mathrm{~W} / \mathrm{m}^{2}\right)$ per day. During November and December, solar irradiation was at its weakest, reaching between 200 and 300 $\mathrm{Btu} / \mathrm{ft}^{2}\left(630\right.$ and $\left.945 \mathrm{~W} / \mathrm{m}^{2}\right)$ per day.

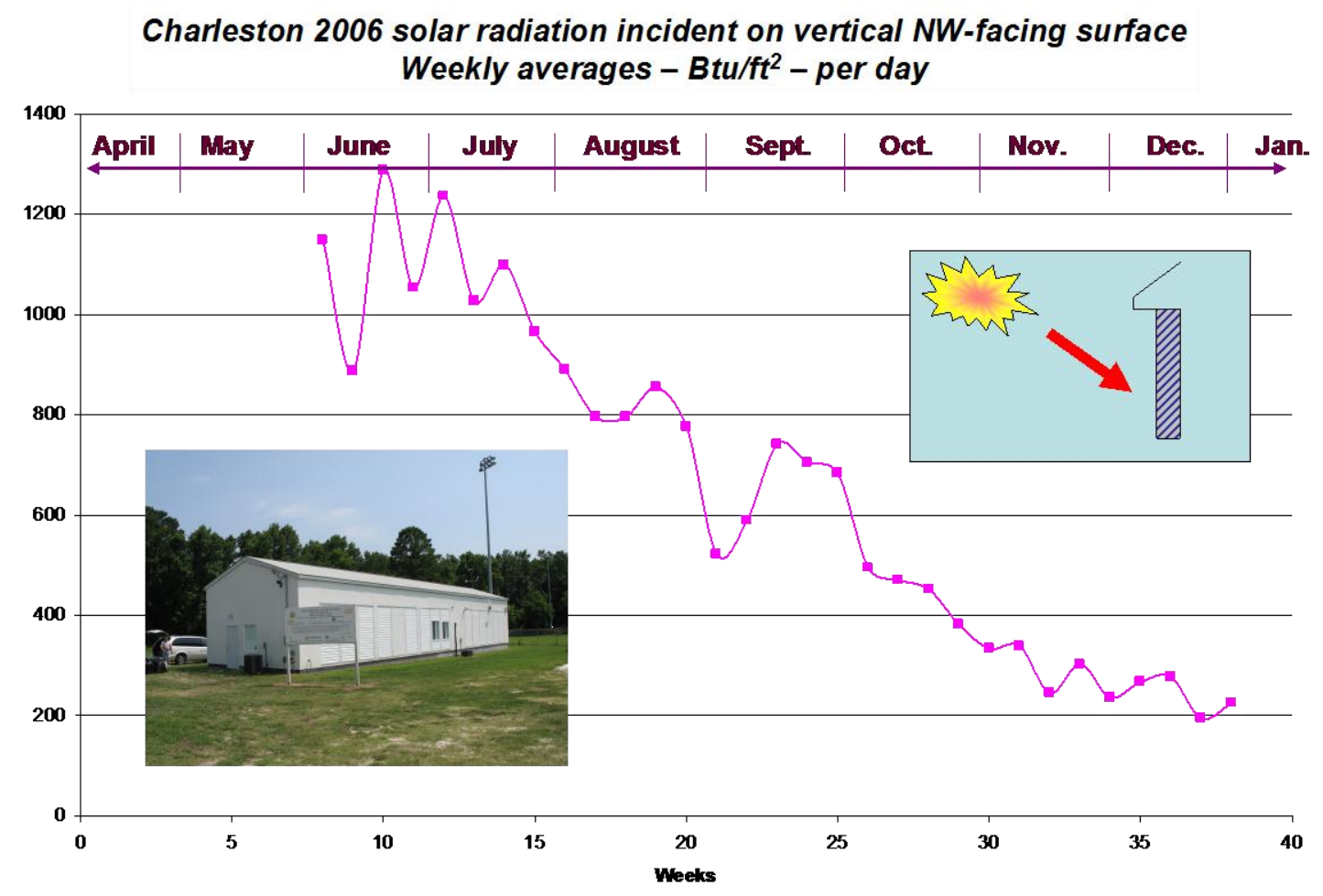

Figure 21. Measured solar radiation on the northwest-facing wall of the Charleston test facility.

Temperature measurements for the interior and ambient air are presented in Figure 22. In addition, maximum, minimum, and average temperatures were recorded for each day. The interior air temperature was kept at about $69^{\circ} \mathrm{F}\left(20^{\circ} \mathrm{C}\right)$ - about $10^{\circ}$ below the level of the theoretical melting point of the PCM. During the summer months, the maximum daily temperatures exceeded $95^{\circ} \mathrm{F}\left(35^{\circ} \mathrm{C}\right)$; at the same time, the minimum daily temperatures were between 60 and $70^{\circ} \mathrm{F}\left(16\right.$ and $\left.21^{\circ} \mathrm{C}\right)$. During December (the coldest month), minimum temperatures oscillated between 17 and $77^{\circ} \mathrm{F}\left(-8\right.$ and $\left.+25^{\circ} \mathrm{C}\right)$.

Exterior surface temperatures for both walls were close, usually varying during most days by no more than $2^{\circ} \mathrm{F}\left(1^{\circ} \mathrm{C}\right)$. As shown in Figure 23, for the wall containing PCM, the maximum wall surface temperatures were not as high as during the Oak Ridge experiment. The maximum wall surface temperatures during the summer reached $105^{\circ} \mathrm{F}\left(41^{\circ} \mathrm{C}\right)$. For the following months, these temperatures fell, reaching $75^{\circ} \mathrm{F}\left(24^{\circ} \mathrm{C}\right)$ in December. Figures 22 and 23 show that the minimum temperatures for the exterior wall surface and for the ambient air were very close. 


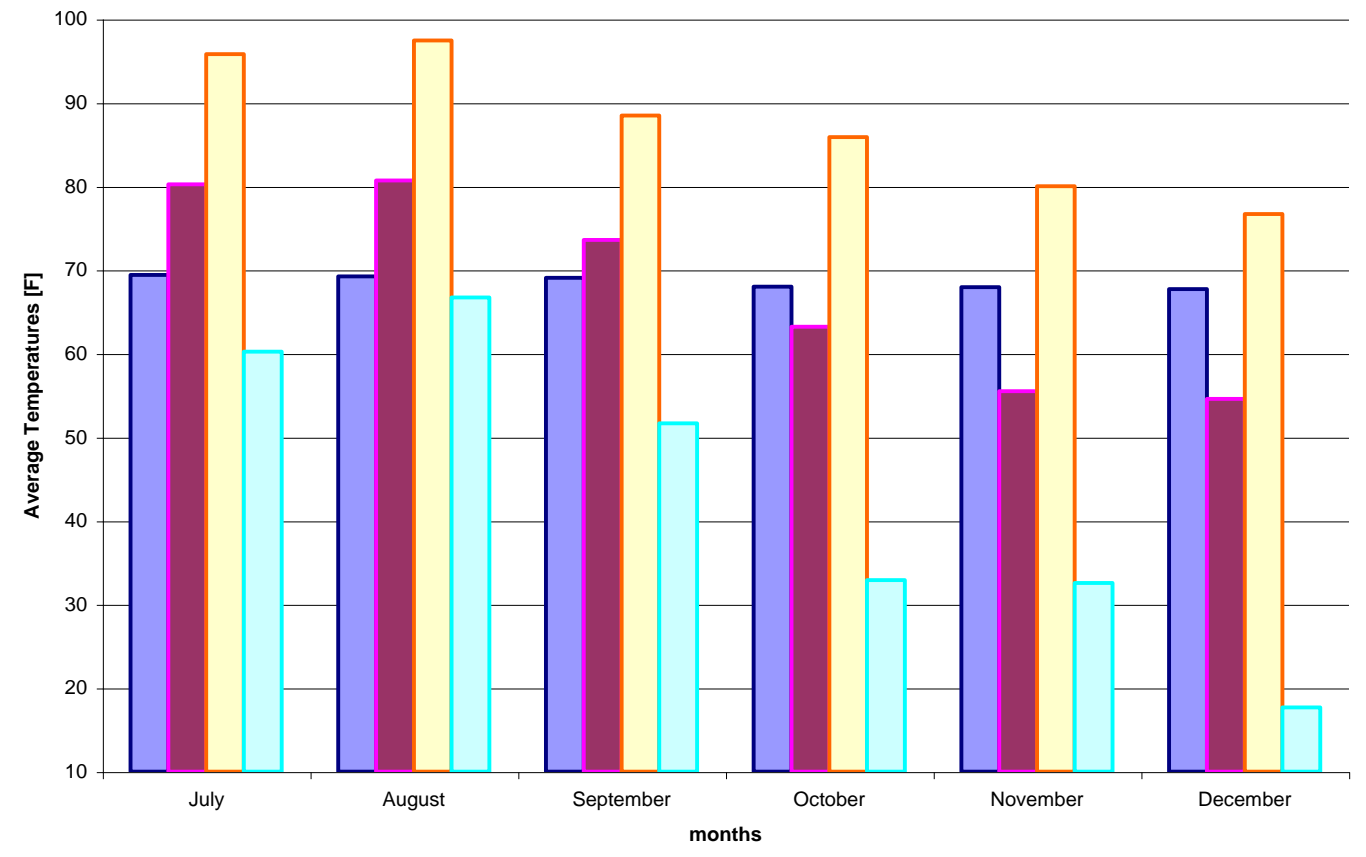

口int. air $\mathbf{m}$ ambient air $\square$ amb. Max $\square$ amb. Min

Figure 22. Interior and ambient air temperatures recorded during the PCM field experiment in Charleston.

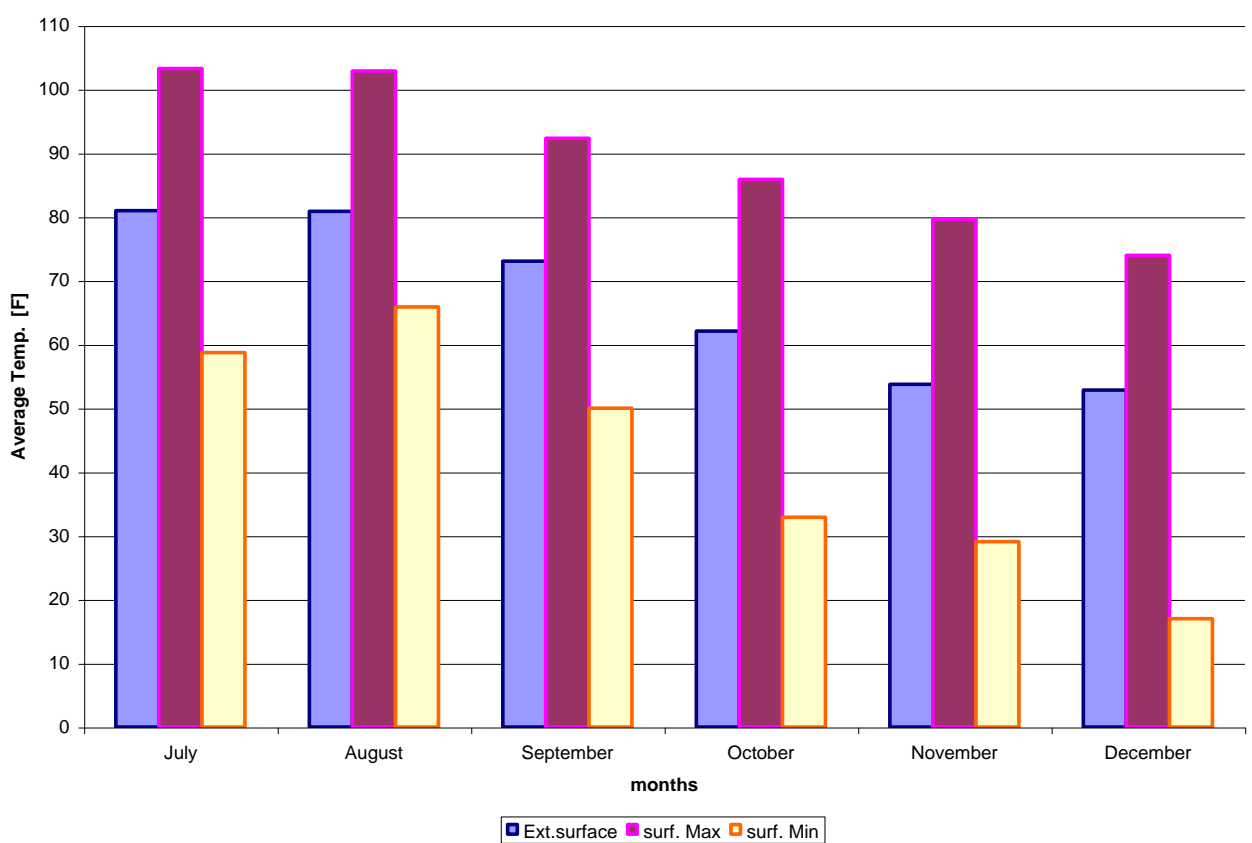

Figure 23. Exterior PCM wall surface temperatures measured during the Charleston field experiment. 


\section{Internal Wall Temperature Profiles}

During the Charleston experiment, experimental walls were instrumented like those in Oak Ridge. Analysis of the temperature profiles was necessary to evaluate how effectively the PCM worked during different temperature swings. Heat flows on the surfaces of both walls were measured using heat flux transducers located on the internal surfaces of the wall sheathing materials (facing the wall cavity for greater accuracy).

During both 2006 field experiments, special attention was given to determining how much of the PCM was going through the phase change process during the daily dynamic thermal excitations. Figure 24 demonstrates temperature profiles for a series of the first four days of July 2006, when the PCM operated under optimum conditions (e.g., for the northwest-oriented wall). In this chart, temperature profiles of the wall containing PCM are marked with thicker lines and those of the walls without PCM with thinner lines. Significant differences in temperature profiles can be observed for the center-of-cavity location in both tested walls. PCM microcapsules were thermally stabilizing the core of the wall with their heat storage capacity. A time delay of about 2 hours was observed in the center of the PCM wall. Temperature profiles recorded in both walls during July 2006 are presented in Figure 25. The maximum wall surface temperatures in July reached $107^{\circ} \mathrm{F}\left(42^{\circ} \mathrm{C}\right)$ for only two days. In general, exterior surface temperatures cycled between $105^{\circ} \mathrm{F}\left(41^{\circ} \mathrm{C}\right)$ during the days and $70^{\circ} \mathrm{F}\left(21^{\circ} \mathrm{C}\right)$ during most nights.

For 31 weeks of the Charleston field tests, analysis of the temperature profiles in the tested walls showed that the PCM was going through charging and full discharging processes during most 24-hour time periods. However, the temperatures of the exterior wall surfaces were not as high as in Oak Ridge. Average monthly temperatures of the center-of-cavity location in the PCM wall are presented in Figure 26. It can be seen that during November and December, the maximum temperatures of the center of the wall cavity did not reach $75^{\circ} \mathrm{F}\left(24^{\circ} \mathrm{C}\right)$. That means that only a small portion of the PCM in the wall was going through the phase change process at that time.

\section{Recorded Heat Flows}

As shown in Figure 22, the temperature of the interior of the building was kept at about $69^{\circ} \mathrm{F}$ $\left(20^{\circ} \mathrm{C}\right)$, which was about $10^{\circ}$ below the level of the theoretical melting point of the PCM used. Consequently, a significant part of the energy stored by the PCM was discharged into the building interior, lowering the effectiveness of the PCM. As a result, total cooling load reductions during the entire summer of 2006 were below 5\%. Simply put, the Charleston PCM was not operating in optimum conditions as was the PCM wall in Oak Ridge.

However, the Charleston PCM wall demonstrated great ability to shave and shift peak cooling loads (heat flows directed to the interior of the building). Figure 27 shows maximum peak-hour heat fluxes recorded in both test walls in Charleston during July 2006. It can be observed that wall-generated peak-hour cooling loads were lower in the PCM wall by about $29 \%$. 


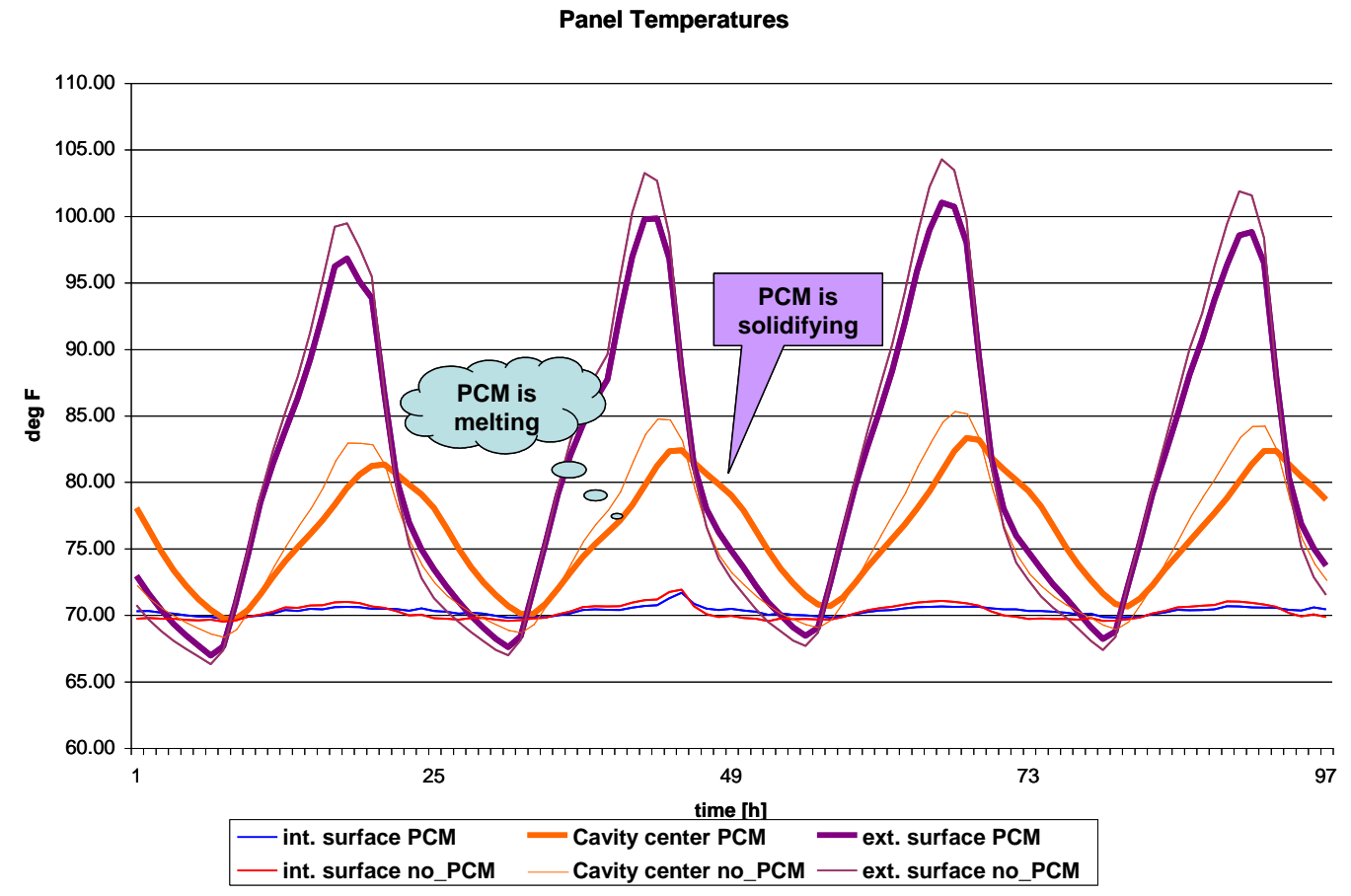

Figure 24. Comparison of temperatures recorded inside the cavities of tested walls during the Charleston field tests.

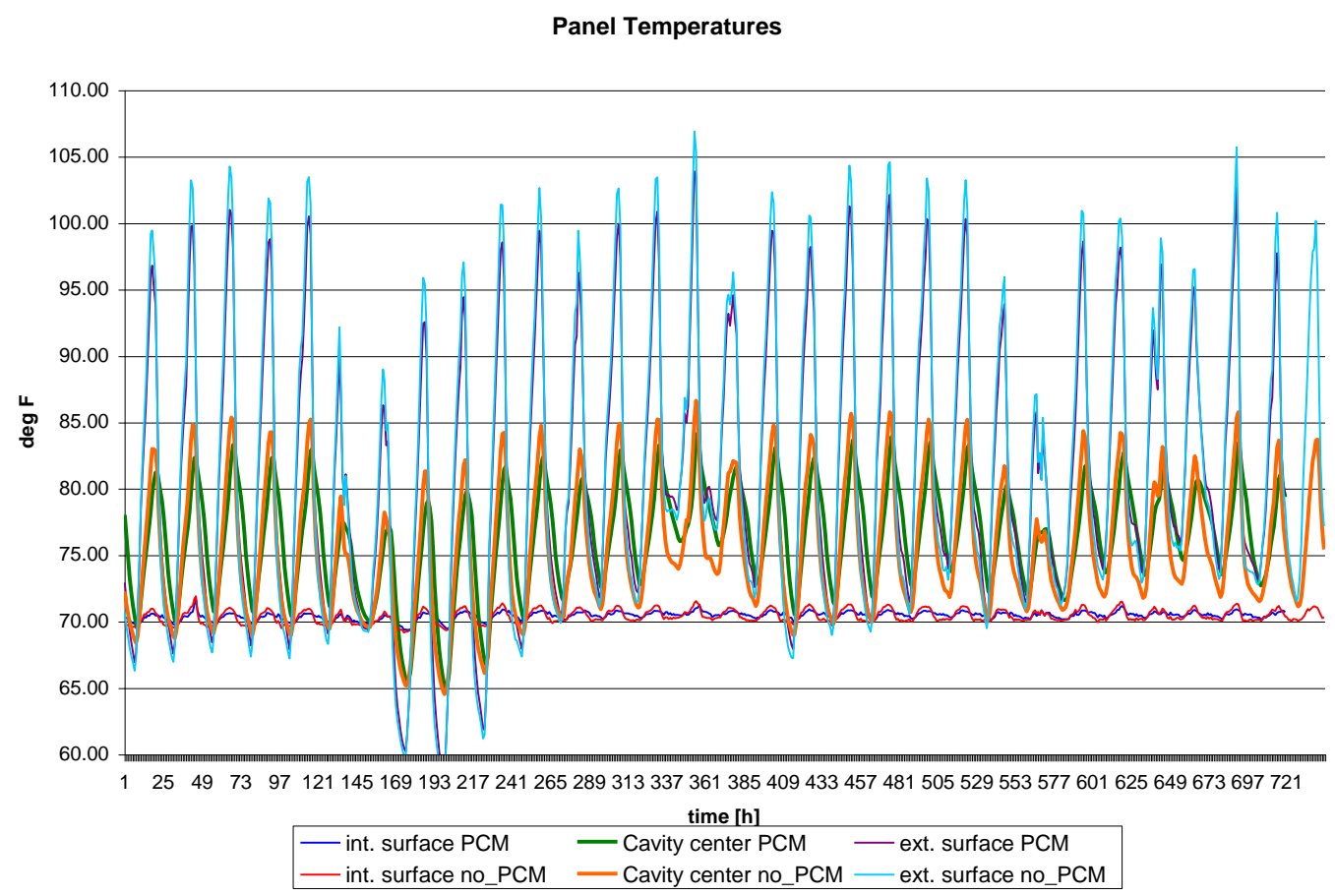

Figure 25. Comparison of temperature profiles recorded during July 2006 in Charleston. 
PCM wall - center of cavity

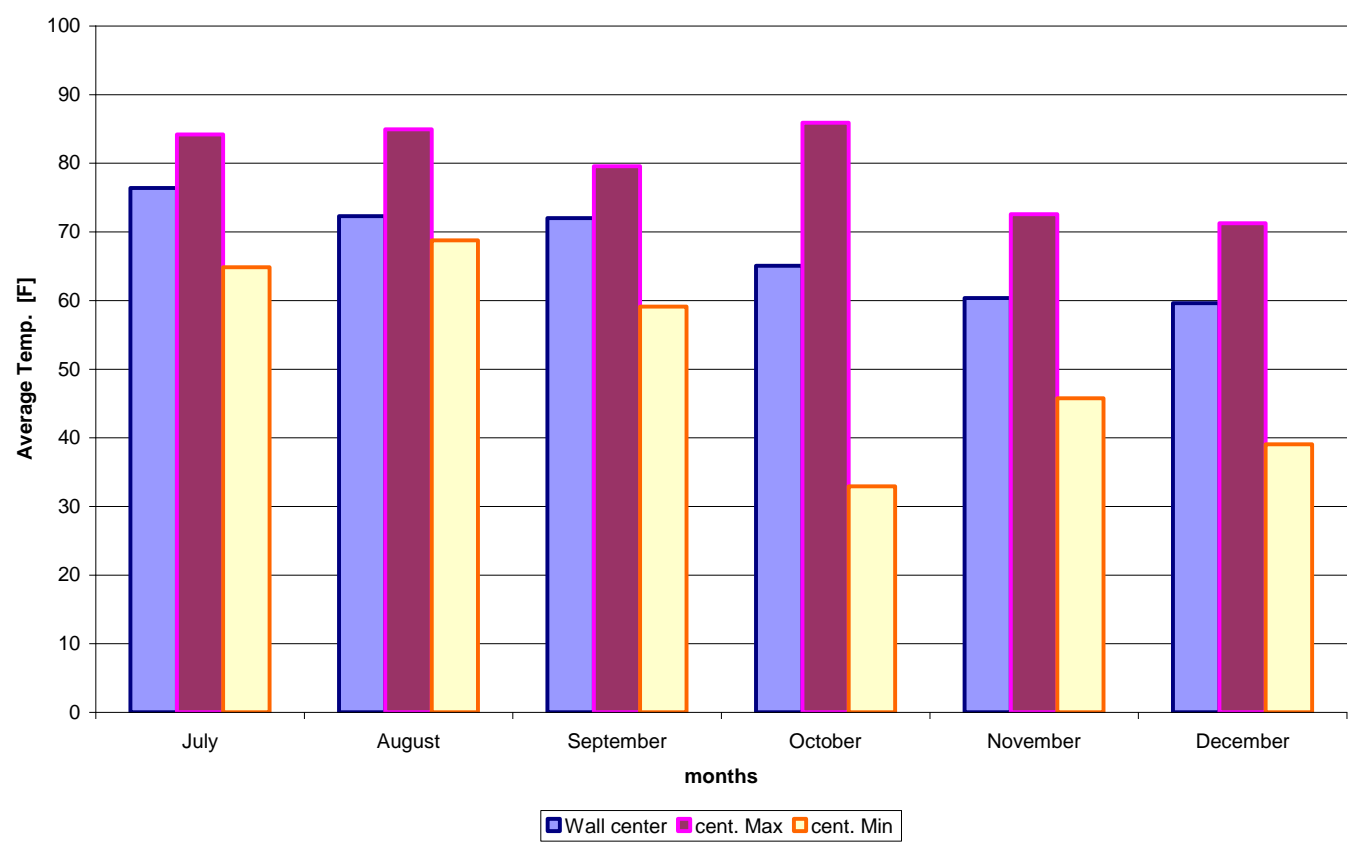

Figure 26. Average monthly temperatures recorded in the center of the wall cavity in the Charleston PCM wall.

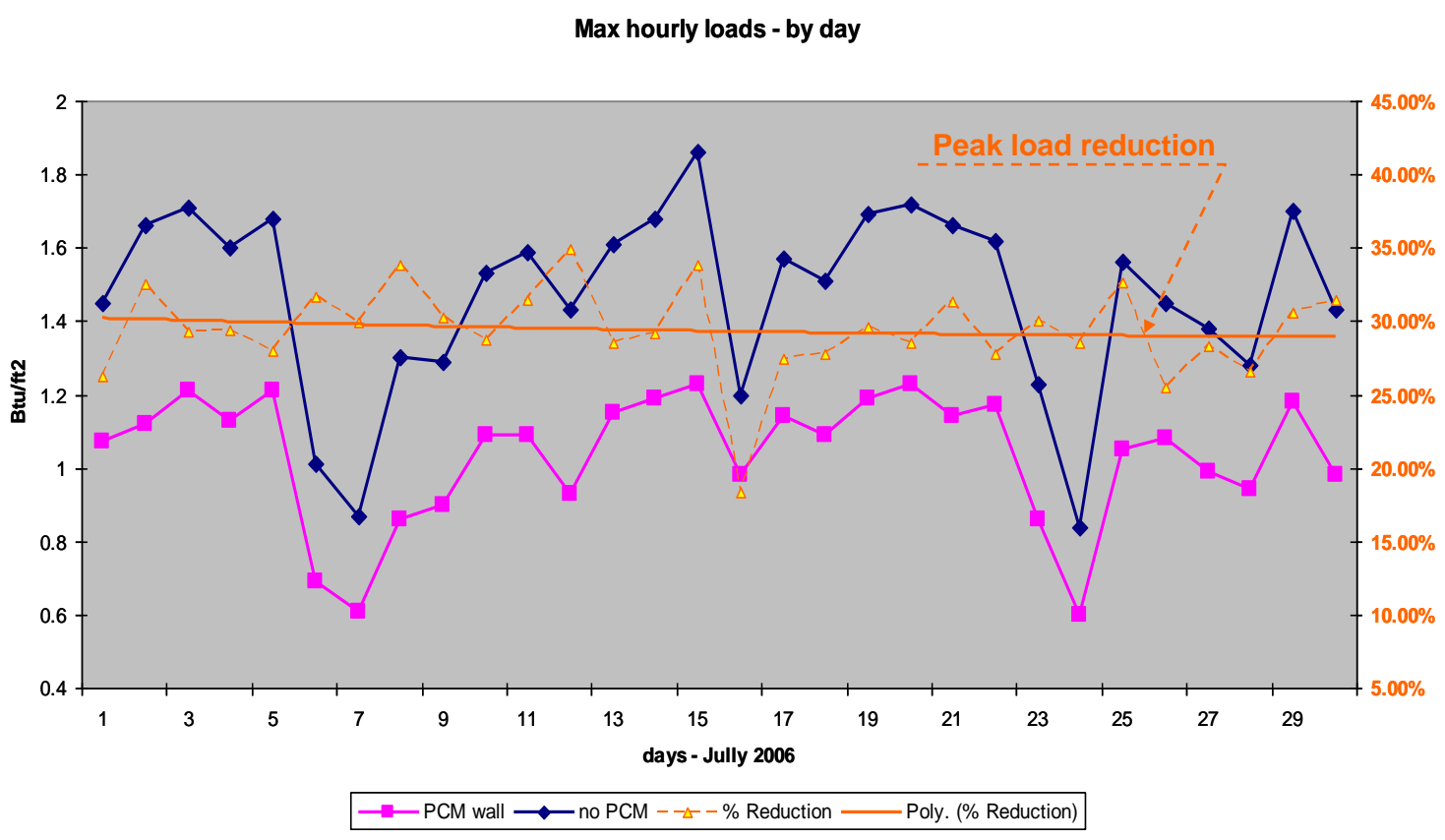

Figure 27. Comparison of the maximum peak-hour heat fluxes recorded during July 2006 in Charleston. 
Table 1 shows more detailed data on peak load reductions and average lag times for the summer months of 2006. On average, the Charleston wall that contained PCM yielded peak-hour cooling loads that were about $27 \%$ lower during the entire summer of 2006. Part of this energy was later released to the interior of the building during the nighttime. The average time by which load was shifted was about 1.6 hour for the PCM wall.

Table 1. Reduction of wall-generated cooling peak-hour load recorded on the Charleston PCM wall, during summer months 2006

\begin{tabular}{lcccc}
\hline Peak-hour loads & June & July & August & September \\
$\%$ reduction & $30 \%$ & $29 \%$ & $31 \%$ & $18 \%$ \\
Lag time $[\mathrm{h}]$ & 1.6 & 1.4 & 1.6 & 1.7 \\
\hline
\end{tabular}

An example of the daily heat flux profiles is presented for the last 10 days of June 2006 in Figure 28. It is notable that for the PCM wall, the peak-hour cooling load was reduced by about $1 / 3$ during the daytime and cooling loads during the night were slightly higher than for the wall containing no PCM. In addition, a delay of approximately 2 hours in transferring the heat flow excitations can be observed.

In general, the Charleston experiment confirmed the ability of PCM-enhanced cellulose insulation to reduce and shift cooling loads. As stated earlier, because there was a difference of about $10^{\circ}$ between the interior building air temperature and the PCM melting point, the PCM

Example of results from Charleston experiment for last 10 days of June 2006

Heat Flow (int. surf)

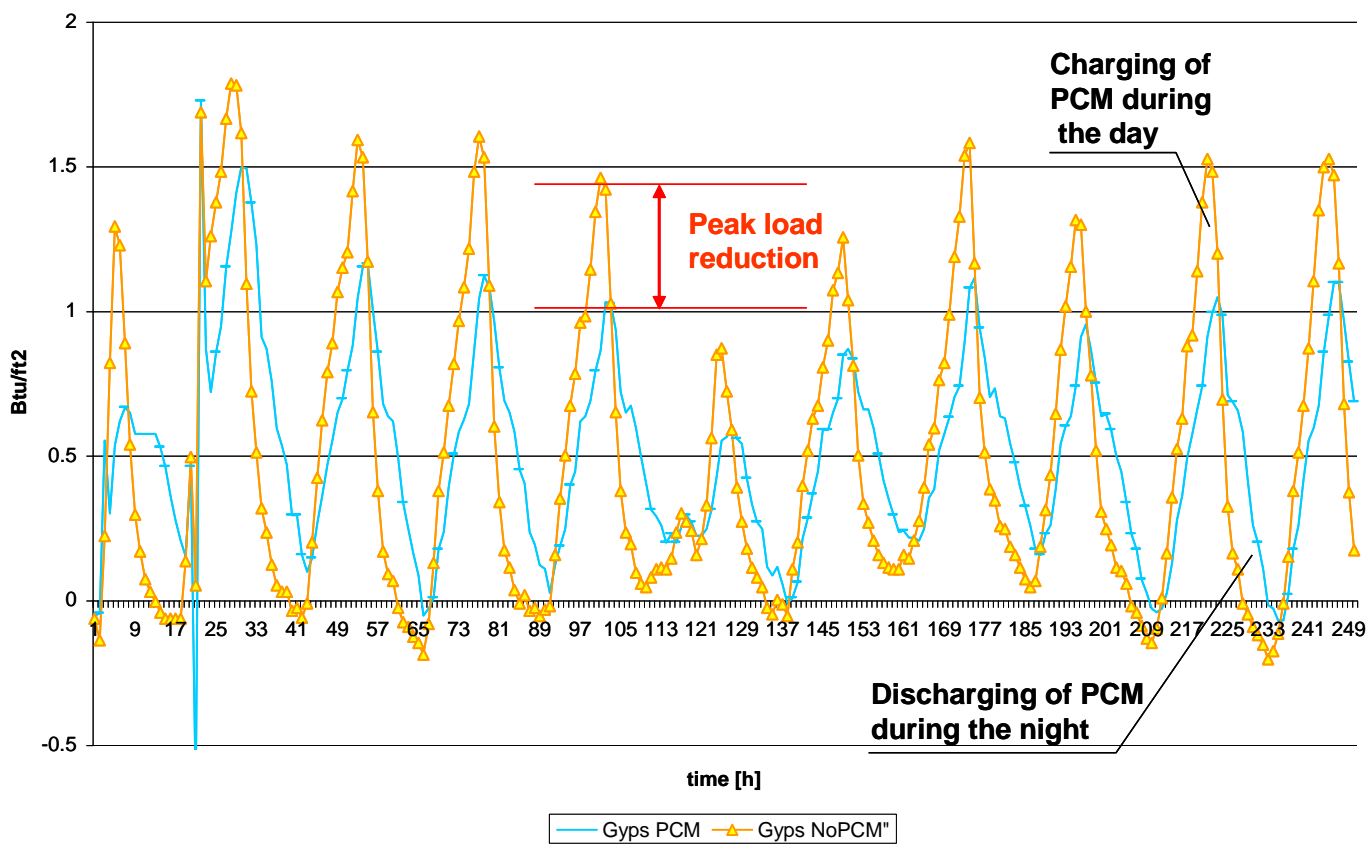

Figure 28. Surface heat fluxes recorded during June 2006. 
microcapsules were not working in optimum thermal conditions (in the Oak Ridge experiment, this temperature difference was close to zero). In addition, during July and August, the average temperatures of the exterior surfaces of both walls were close to $80^{\circ} \mathrm{F}\left(27^{\circ} \mathrm{C}\right)$, a condition that made full discharge of the PCM by the ambient air difficult. These two facts were probably the main reasons that the overall cooling load was reduced by less than $5 \%$ during the summer of 2006. Simply, heat stored by the PCM flowed more often from the center of the cavity to the interior of the building (which was significantly cooler during the most of the time).

\section{OPTIMUM CLIMATIC AND THERMAL CONDITIONS FOR PCM IN COOLING- DOMINATED CLIMATIC CONDITIONS}

Long-term field testing of two walls containing PCM-enhanced cellulose insulation helped to answer many questions regarding the energy performance of this new material. In both locations, the PCM worked relatively well. However, it was evident that in Oak Ridge, because of the southern wall orientation, the PCM installed inside the wall cavity worked more efficiently compared with traditional insulation. As a result of higher temperature fluctuations on the exterior surfaces of the Oak Ridge walls, more PCM was going through a complete phasechange process. These two experiments demonstrated the importance of properly selecting a climate (or PCM melting temperature) for PCM application in residential buildings. During the 2006 PCM experiments, the ORNL research team was considering only one type of PCM; this part of the report is focused only on defining the most favorable climatic conditions for this one specific PCM. This task may help in pre-selection of the most favorable geographic locations for application of the PCM-enhanced cellulose without going into the time-consuming whole building energy modeling.

Based on the calorimetric measurement data presented in Figure 3, the mean melting point of the PCM used was about $78.5^{\circ} \mathrm{F}\left(25.8^{\circ} \mathrm{C}\right)$. The total phase change enthalpy for the PCM was $52 \mathrm{Btu} / \mathrm{lb}(121 \mathrm{~J} / \mathrm{g})$. Detailed temperature profiles inside the wall cavity are presented in Figure 15 for the PCM wall installed in Oak Ridge. It can be seen that under the field conditions, the PCM (when mixed with cellulose fibers) was melting at $77-82^{\circ} \mathrm{F}\left(25-28^{\circ} \mathrm{C}\right)$. The temperature range for the PCM solidification process was $81-83^{\circ} \mathrm{F}\left(27-28.5^{\circ} \mathrm{C}\right)$.

As presented in Figures 13, 14, 15, 24, and 25, detailed monitoring of the temperature distributions inside the wall cavities took place during both field experiments. Analysis of the recorded temperature profiles yielded the following conclusions regarding the optimum thermal conditions for using PCM when cooling loads dominate.

1. Peak temperatures on the exterior wall surface should be no higher than $110^{\circ} \mathrm{F}\left(43^{\circ} \mathrm{C}\right)$. This translates into total wall irradiation of 600 to $1400 \mathrm{Btu} / \mathrm{ft}^{2}\left(1890\right.$ to $\left.2205 \mathrm{~W} / \mathrm{m}^{2}\right)$ per day. If total solar radiation is higher, the storage capacity of the PCM may be too small to thermally stabilize the wall.

2. The minimum nighttime temperature of the exterior wall surface should be between 65 and $40^{\circ} \mathrm{F}\left(17\right.$ and $\left.4^{\circ} \mathrm{C}\right)$. This condition is very important for proper discharge of the PCM during the night. 
3. During the peaks, the temperature of the PCM-enhanced insulation in the middle of a $2 \times 6$ wall cavity should be higher than $85^{\circ} \mathrm{F}\left(29^{\circ} \mathrm{C}\right)$. This temperature in the center of the wall cavity is sufficient for about 50 to $60 \%$ of the wall PCM to complete the melting process.

Eleven U.S. locations were considered to determine whether any of them met the optimum climatic conditions for PCM application: Atlanta; Bakersfield, CA; Chicago; Denver; Fort Worth, TX; Knoxville, TN; Miami; Minneapolis; Phoenix, AZ; Seattle; and Washington, D.C.

In this analysis, solar irradiation was represented in the form of the total solar radiation on the south-oriented vertical wall. It was computed using Duffie and Beckman (1980) and Balcomb et al. (1983). The relationship between the normal daily value of total hemispheric radiation incident on the horizontal surface $\left(\mathrm{H}_{\mathrm{sol}}\right)$ and the normal daily value of total hemispheric radiation incident on the vertical wall surface $\left(\mathrm{V}_{\text {sol }}\right)$ was expressed using the following correlations:

$V_{\text {sol }}=H_{\text {sol }}\left[\left(0.6866-0.6623 \mathrm{Y}+1.3269 Y^{2}\right)+K_{T}\left(-0.4458+0.3090 Y+4.776 Y^{2}\right)\right]$

where

$\mathrm{Y}=(\mathrm{LAT}-\mathrm{Dec}) / 100$,

LAT is latitude (degrees) and DEC is mid-month solar declination (degree)

$\mathrm{K}_{\mathrm{T}}$ is average monthly clearness ratio.

Figure 29 shows average monthly values of total hemispheric radiation incident on the vertical wall surface in the 11 U.S. locations considered. Wall irradiation of between 600 and $1400 \mathrm{Btu} / \mathrm{ft}^{2}$ per day is marked as the optimum condition. Next, the impact of fluctuations in the exterior air temperature on the melting and freezing processes within the PCM microcapsules was analyzed. For this purpose, monthly degree-days below $70^{\circ} \mathrm{F}\left(21^{\circ} \mathrm{C}\right)$ were used for each location (DD70). Degree-days were calculated by the method described by Thom (1954). 


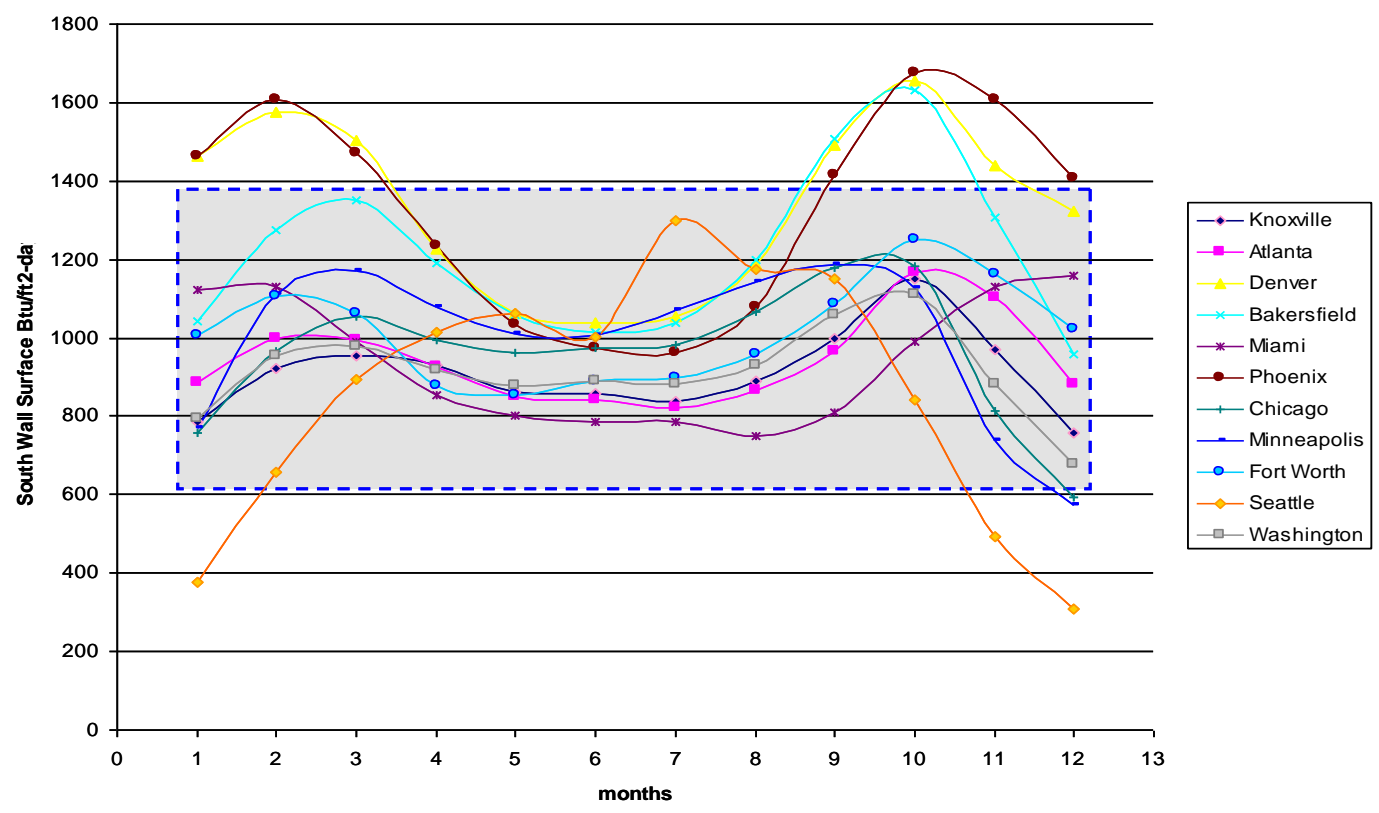

Figure 29. Average monthly values of total hemispheric radiation incident on the vertical wall surface; shaded area represents the optimal conditions for one specific PCM in a cooling-dominated mode.

In addition, monthly averages between maximum and minimum ambient temperatures were calculated for each location. Figures 30 and 31 present a graphic analysis of optimum temperature conditions for PCM application. Based on observations from the Oak Ridge and Charleston field studies, it was assumed that for proper charge and discharge of the PCM, the mean temperature should not be lower than $50^{\circ} \mathrm{F}\left(10^{\circ} \mathrm{C}\right)$ and not higher than $85^{\circ} \mathrm{F}\left(29^{\circ} \mathrm{C}\right)$. Similarly, the DD70 should not be lower than 50 per month (to enable discharge of the PCM). As a maximum number of degree-days, a DD70 of 600 was assumed.

Combining temperature and solar irradiation requirements from Figures 29 through 31, a simple time-chart was developed showing the potentially best months for application of PCM-enhanced cellulose in the locations considered. The chart is presented in Figure 32. Dashed lines represent months when the performance of PCM needs to be investigated by additional field testing. In most cases, the authors are not sure how effectively PCM can be discharged during the summer months. 


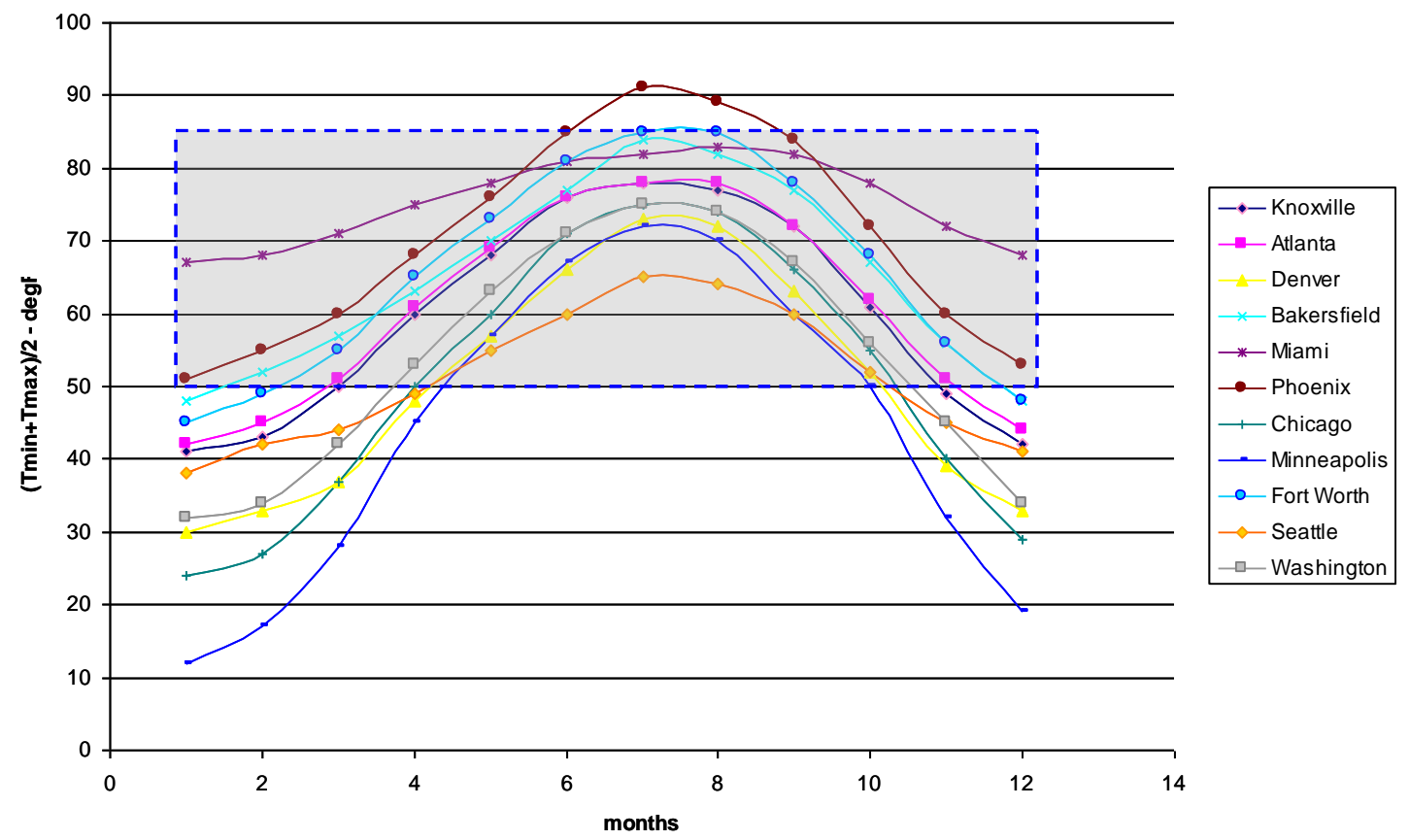

Figure 30. Monthly averages between maximum and minimum ambient temperatures

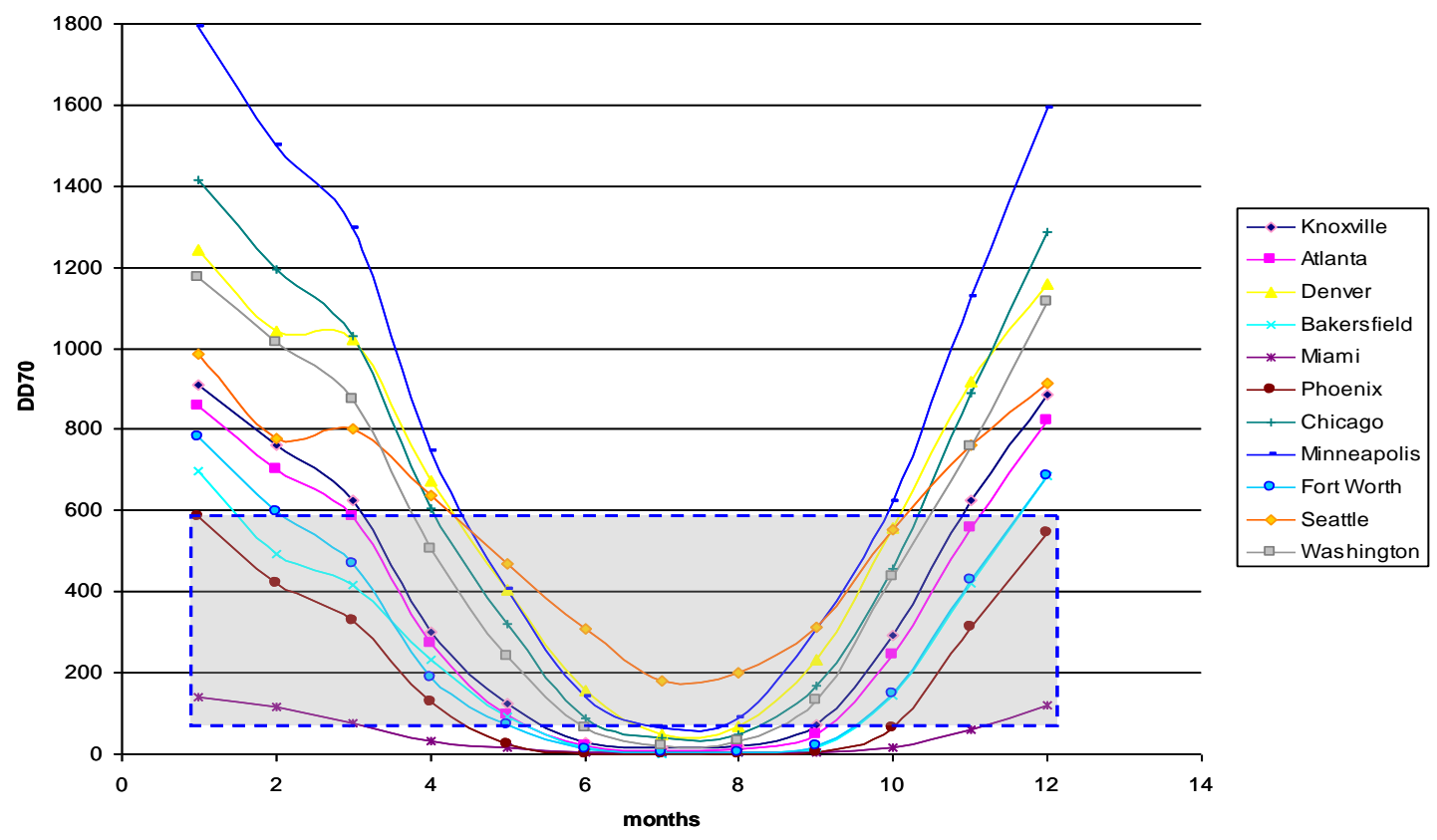

Figure 31. Optimum degree-days DD70 for application of PCM-enhanced cellulose 


\begin{tabular}{|l|l|l|l|l|l|l|l|l|l|l|l|l|}
\hline & Jan & Feb & Mar & Apr & May & June & July & Aug & Sept & Oct & Nov & Dec \\
\hline Atlanta & & & & & & & & & & & \\
\hline
\end{tabular}

Figure 32. Solid lines show the best months for the use of PCM-enhanced cellulose insulation.

The general finding from this analysis is that the most efficient application of this particular PCM-enhanced cellulose insulation will be in locations with mixed climates or during the midseason months in locations with cooling-dominated climates. Figure 33 shows the expected number of months with optimum climatic conditions for the use of this particular PCM-enhanced cellulose insulation. (Knoxville, TN, is marked as a location where PCM can operate under optimum thermal conditions for more than 8 months of the year.) The findings reflect the fact that for many locations - such as Atlanta, Miami, Bakersfield, and Fort Worth-more work is necessary to determine the optimal PCM properties and postioning necessary for full utilization of the PCM during the summer months. These situations are marked on Figure 33 as "Possible." 


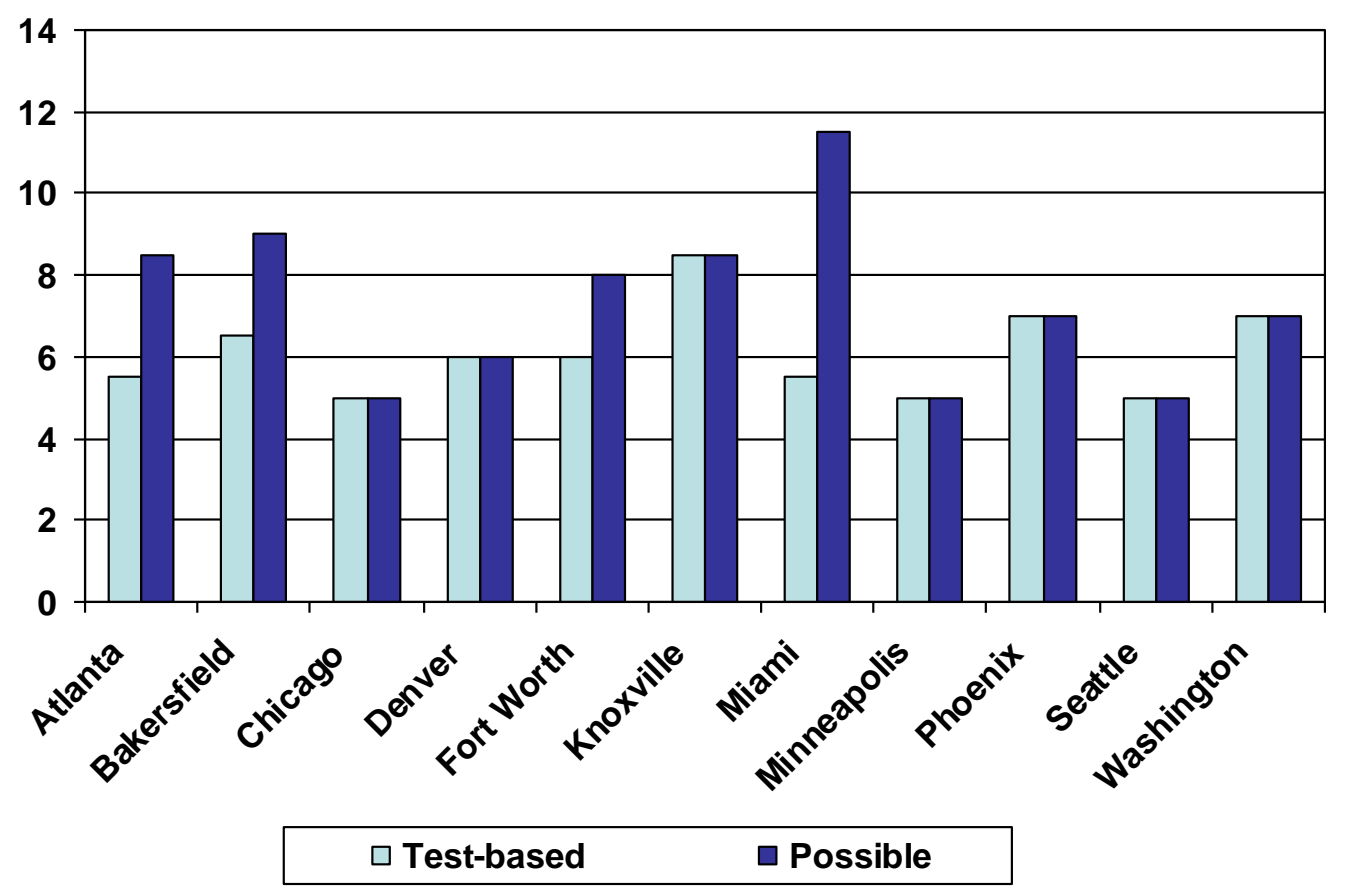

Figure 33. Predicted number of optimum months for application of PCM-enhanced cellulose insulation.

\section{BASIC COSTS ASSOCIATED WITH PRODUCTION OF PCM-ENHANCED CELLULOSE INSULATION}

This portion of the report reflects a preliminary economic analysis of the newly developed insulation product. There is a lack of current price information on microencapsulated PCM on the U.S. market. In addition, production costs may be different for different material producers. The energy analysis supporting this study is based on limited experimental data coming from the Oak Ridge field experiment. A more detailed analysis, using whole-building energy simulations and parametric analysis for ten U.S. locations, is planned.

The basic costs of production of the cellulose insulation were analyzed based on data provided by U.S. Green Fiber (The largest U.S. producer of cellulose fiber insulation with $\sim 60 \%$ of the market) and Advanced Fiber Technology (a company that collaborated in the ORNL PCM project from its beginning). The cost of microencapsulated PCM was estimated based on the data provided by BASF (a German company that provided most of the microencapsulated PCM for the project), Microtek (a U.S. company in Dayton, Ohio, that supplied microencapsulated PCM for ORNL testing), and Mitsubishi Chemicals of Japan. All the companies were asked to estimate the future cost of microencapsulated PCM assuming a large-volume supply for the U.S. market.

In 2003, when ORNL began the PCM project, BASF predicted its large-volume price as between $\$ 1.15$ and $\$ 1.5$ per lb. During the following years, partly as a result of the significant increase in the cost of crude oil and partly because of a large demand for PCM in Europe, the U.S. price for small-volume transactions has been between $\$ 4$ and $\$ 5$ per lb. PCM producers estimate that in 
case of large-volume production (for example, caused by demand for PCM-enhanced insulation) this price could be reduced by 40 to $50 \%$.

The paraffinic PCM represents only about 60 to $75 \%$ weight of the microcapsule (depending on the producer); the remaining material is typically an acrylic or melamine skin. The paraffinic core represents only $25-30 \%$ of the total price (depending on the producer); the microencapsulation is the major price component in this type of product. In that light, most of the PCM price increases announced by producers are probably related more to market demand than to the elevated price of crude oil. In spring 2007, BASF started to consider moving its PCM production from Germany to the United States. Its projected large-volume price should be between $\$ 2.0$ and $\$ 2.5$ per lb. That is why a PCM price of $\$ 2.5$ per lb is used as a baseline in the following economic analysis.

The author estimated a range of prices for PCM-enhanced cellulose insulation assuming that the price of the PCM microcapsules will be between $\$ 1.15$ and $\$ 5.0$ per lb. Two compositions of PCM-enhanced cellulose were considered $-10 \%$ and $20 \%$ by weight. Based on the data provided by the Knoxville, TN, Lowe's store (in July 2007), the price of the $22 \mathrm{lb}$ bag was $\$ 7.97$, which yields a price of about $\$ 0.36$ per $\mathrm{lb}$. Based on this price, a $30 \mathrm{lb}$ bag would cost about $\$ 10.90$. After assuming $60 \%$ for profit and transportation costs, the wholesale price of the $30 \mathrm{lb}$ bag was estimated as $\$ 4.36$ and about $\$ 0.14$ per $1 \mathrm{~b}$. The results of the price analysis for PCMenhanced cellulose are presented in Tables 2 and 3 for PCM content of $10 \%$ and $20 \%$ by weight, respectively. Prices for the PCM-enhanced cellulose presented in Tables 2 and 3 are based on the wholesale cost estimates provided by U.S. Green Fiber and Advanced Fiber Technology. The authors of this report anticipate that the final blends of cellulose and PCM will contain between 10 and $20 \%$ of microencapsulated PCM by weight, depending on the application (attic applications may contain less PCM).

Table 2. Cost of PCM-enhanced cellulose for a blend of 10\% PCM by weight (in U.S. \$)

\begin{tabular}{|l|l|l|l|}
\hline \multicolumn{1}{|c|}{ PCM per lb } & \multicolumn{1}{|c|}{$\begin{array}{c}\mathbf{3 0 - l b} \text { bag } \\
\text { of insulation }\end{array}$} & $\begin{array}{c}\text { Insulation for } \mathbf{1} \mathbf{f t}^{\mathbf{2}} \text { cavity } \\
\text { in } \mathbf{2 \times 4} \text { wall }\end{array}$ & $\begin{array}{c}\text { Insulation for 1-ft } \\
\text { cavity in } \mathbf{2} \times \mathbf{6} \text { wall }\end{array}$ \\
\hline $\begin{array}{l}\text { No PCM - Lowe's } \\
\text { wholesale price }\end{array}$ & 4.36 & 0.11 & 0.17 \\
\hline$\$ 2.50$ & 9.18 & 0.23 & 0.36 \\
\hline
\end{tabular}

Table 3. Cost of PCM-enhanced cellulose for a blend of $20 \%$ PCM by weight (in U.S. \$)

\begin{tabular}{|c|c|c|c|}
\hline PCM per lb & $\begin{array}{c}30 \text { lb bag } \\
\text { of insulation }\end{array}$ & $\begin{array}{c}\text { Insulation for } 1 \mathrm{ft}^{2} \text { cavity } \\
\text { in } 2 \times 4 \text { wall }\end{array}$ & $\begin{array}{l}\text { Insulation for } 1-\mathrm{ft}^{2} \\
\text { cavity in } 2 \times 6 \text { wall }\end{array}$ \\
\hline $\begin{array}{l}\text { No PCM- } \\
\text { Lowe's whole- } \\
\text { sale price }\end{array}$ & 4.36 & 0.11 & 0.17 \\
\hline$\$ 2.50$ & 16.54 & 0.42 & 0.66 \\
\hline
\end{tabular}

\section{Economic Evaluation of Application of PCM-Enhanced Cellulose Insulation in Residential Buildings}

During a 12-month period starting in April 2006, small-scale field testing of PCM-enhanced cellulose insulation was performed in two U.S. locations - Oak Ridge, Tennessee, and 
Charleston, South Carolina. As discussed in previous chapters, the Oak Ridge tests demonstrated a potential for an average reduction of about $42 \%$ in cooling loads through the walls during the cooling season. These target energy savings were used for the cost evaluations presented in this section.

Field test data collected during 2006-2007 also demonstrated significant peak-hour load reductions. However, because few residences are eligible for demand pricing, or even time-ofday pricing, potential cost benefits associated with peak-hour load reductions were not evaluated in this project.

To aid in the cost analysis, a series of DOE-2.1E whole-building energy simulations were performed. Since experimental data on thermal performance were available only for wall assemblies, only wall-generated loads and their dependence on wall R-values were considered. These simulations enabled the development of a series of correlation equations linking wall Rvalues with wall-generated heating and cooling loads for the Atlanta area. Because of limited time and available funding, only test performance data collected during the Oak Ridge field experiment were used for the comparisons. The Atlanta climate was selected for the wholebuilding energy simulations. ${ }^{1}$

The DOE-2.1E whole-building simulations were performed for a single-story ranch house which was the subject of previous energy studies (Hasting 1977; Huang et al. 1987; Kossecka and Kosny 1996). To normalize the calculations, a standard building elevation for a single-story ranch style house was used. The house has approximately $1540 \mathrm{ft}^{2}$ of living area, $1328 \mathrm{ft}^{2}$ of exterior (or elevation) wall area, 8 windows, and 2 doors (one door is a glass slider; its impact is included with the windows). The elevation wall area includes $1146 \mathrm{ft}^{2}$ of opaque (or overall) wall area, $154 \mathrm{ft}^{2}$ of window area, and $28 \mathrm{ft}^{2}$ of door area.

Parametric simulations were performed with variable wall R-values (for ten wall configurations ranging from R-2 to R-40). All other building components were kept the same. These simulations enabled the estimation of relationships between wall R-values and whole-building heating and cooling loads. These correlations are depicted in Figures 34-36

\footnotetext{
${ }^{1}$ A new version of Energy Plus with PCM simulation module was introduced in June 2007, after this work was complete.
} 


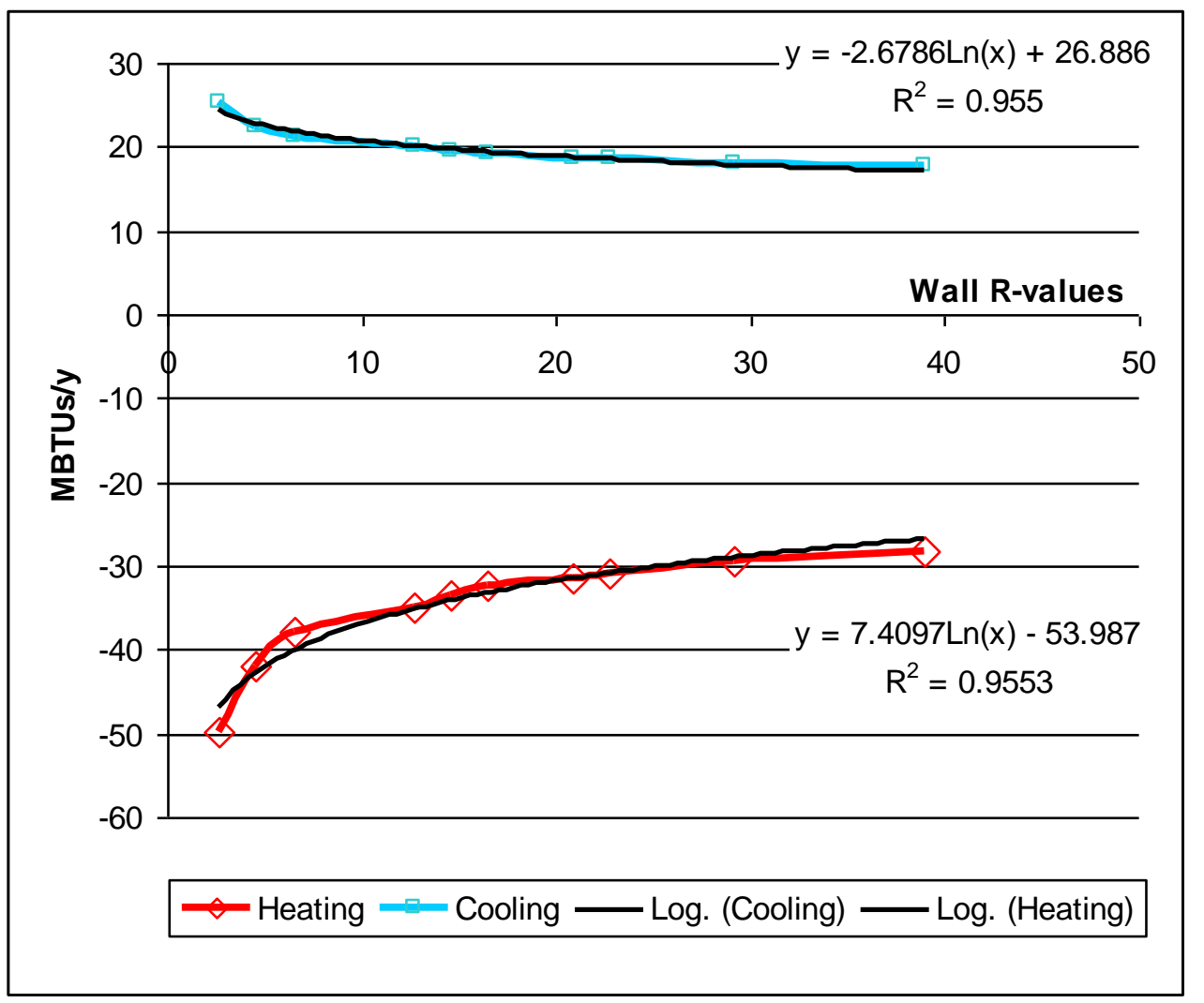

Figure 34. Correlations between wall R-values and whole-building heating and cooling loads generated for a one story residential house by a series of whole-building energy simulations (for the Atlanta climate).

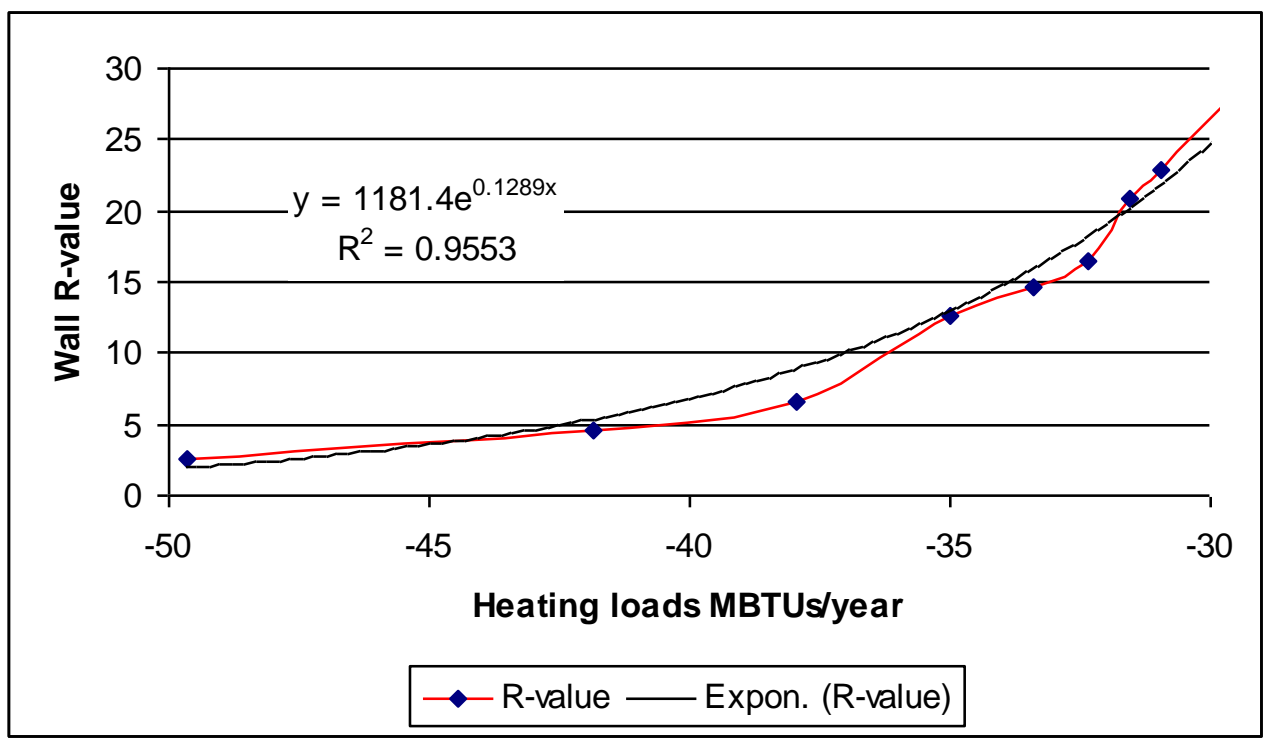

Figure 35. Approximate correlations between whole-building heating loads and wall R-values computed for a one story residential house (for the Atlanta climate). 


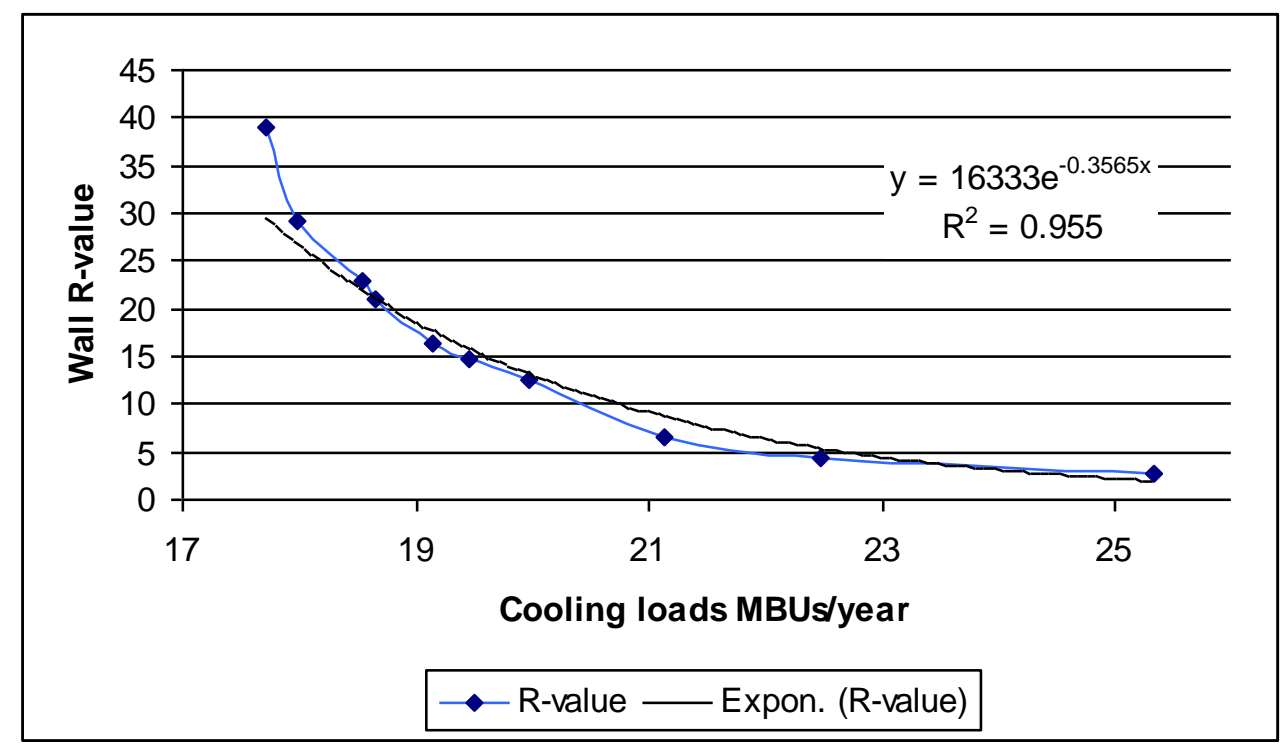

Figure 36. Approximate correlations between whole-building cooling loads and wall R-values computed for a one story residential home (for the Atlanta climate).

It is good to realize that PCMs are not fully thermally equivalent to conventional thermal insulations. Usually PCM building envelopes are optimized for specific range of temperatures, determining if the PCM wall or roof assembly will help in reduction of either cooling, or heating loads - not both of them. It is clear that material of melting point 78deg F cannot work in temperatures below 78deg F, even-thought notable temperature fluctuations can be observed. For example 2006/07 Oak Ridge filed test demonstrated about 40\% savings in cooling loads, but also $16 \%$ savings in heating loads (since PCM was optimized for temperature swings characteristic for cooling season only). Since, field experiments described in previous chapters were focused mainly on the cooling loads, only cost for achieving cooling energy savings is analyzed below. However it is good to note that absolute magnitude of the heating load was much greater than the cooling load. In that light, $16 \%$ of the heating load may represent greater savings than $40 \%$ of the cooling load.

A nominal $2 \times 4$ wood-frame wall was modeled in whole-building energy simulations as a multilayer material assembly with an R-value of 12.65 . This material configuration represents a $2 \times 4$ wall with a cavity insulated with blown cellulose insulation or R-13 fiberglass batts, containing $1 / 2$ in. gypsum board on the interior surface and $1 / 2$ in. oriented stand board (OSB) sheathing and vinyl siding on the opposite side. The framing factor for this wall was about $20 \%$. Basic annual loads generated for the $2 \times 4$ wall for the climate of Atlanta are presented in Table 4 .

\begin{tabular}{|c|c|c|c|c|c|c|c|}
\hline \multicolumn{3}{|c|}{$\begin{array}{c}\text { Heating loads } \\
\text { (MBtu/year) }\end{array}$} & \multicolumn{5}{c|}{$\begin{array}{c}\text { Cooling loads } \\
\text { (MBtu/year) }\end{array}$} \\
\hline Total & Walls & Roofs & Infiltration & Total & Walls & Roofs & Infiltration \\
\hline-34.997 & -9.974 & -5.011 & -11.841 & 19.969 & 3.333 & 3.669 & -0.14 \\
\hline
\end{tabular}

Similarly, a nominal $2 \times 6$ wood-frame wall was modeled in whole-building energy simulations as a multilayer material assembly with an R-value of 16.80 . This material configuration represents a 
$2 \times 6$ wall with a cavity insulated with blown cellulose insulation or R-19 fiberglass batts, containing $1 / 2$ in. gypsum board on the interior surface and $1 / 2$ in. OSB sheathing and vinyl siding on the opposite side. The framing factor for this wall was about $20 \%$. Basic annual loads generated for a $2 \times 6$ wall for the climate of Atlanta are presented in Table 5 .

\begin{tabular}{|c|c|c|c|c|c|c|c|}
\hline \multicolumn{4}{|c|}{$\begin{array}{c}\text { Heating loads } \\
\text { (MBtu/year) }\end{array}$} & \multicolumn{4}{|c|}{$\begin{array}{c}\text { Cooling loads } \\
\text { (MBtu/year) }\end{array}$} \\
\hline Total & Walls & Roofs & Infiltration & Total & Walls & Roofs & Infiltration \\
\hline-32.371 & -7.286 & -5.003 & -11.765 & 19.149 & 2.387 & 3.654 & -0.217 \\
\hline
\end{tabular}

Experimental data (with recorded $42 \%$ cooling load savings) from the Oak Ridge field test of $2 \times 6$ wood-framed walls with PCM-enhanced cellulose insulation were used in this analysis for the Atlanta location. After a series of dynamic hot box and field experiments, it was assumed that a $2 \times 6$ wall framing with studs installed at 16 in. o.c. will be the most common future configuration for an application of PCM-enhanced cellulose. For the purpose of economic analysis, the following conservative scenario was considered:

Only two walls (for example, the southern and the western walls) will perform as well as was recorded during the Oak Ridge experiment - probably the worst possible scenario. In this scenario, PCM is installed only on the south- and west-oriented walls.

As stated earlier, no consideration was made for reduction of the peak-hour loads (because at the present time, residential customers are not typically eligible for such rate structures).

During the computer analysis, a fictitious layer of extruded polystyrene (XPS) foam sheathing was assumed on $2 \times 4$ and $2 \times 6$ walls. The thickness of this layer of XPS foam was designed to provide the same value of cooling load reduction as was predicted for a $2 \times 6$ wall insulated with PCM-enhanced cellulose insulation. As documented in previous chapters, during the Oak Ridge field experiment, a $42 \%$ reduction of cooling loads was recorded. Therefore, for the scenario considered, the wall-generated cooling load was reduced by $21 \%(1 / 2 \times 42 \%)$. Next, a reduction of the total cooling load was computed using the newly adjusted wall-generated cooling load. In that case, it was assumed that only two walls performed as well as during the ORNL field tests. The newly adjusted cooling loads are presented in Table 6.

Table 6. Baseline and adjusted cooling loads (in MBY/year) for the scenario considered

\begin{tabular}{|c|c|c|c|c|}
\hline $\begin{array}{c}\text { Baseline total cooling } \\
\text { load for 2×6 wall with } \\
\mathbf{R - 1 6 . 8}\end{array}$ & $\begin{array}{c}\text { Baseline wall-generated } \\
\text { cooling load for } \mathbf{2 \times 6} \text { wall } \\
\text { with R-16.8 }\end{array}$ & $\begin{array}{c}\text { Load } \\
\text { reduction } \\
\text { factor }\end{array}$ & $\begin{array}{c}\text { Adjusted wall- } \\
\text { generated } \\
\text { cooling load }\end{array}$ & $\begin{array}{c}\text { Adjusted } \\
\text { total cooling } \\
\text { load }\end{array}$ \\
\hline 19.149 - from Table 5 & 2.387 -from Table 5 & $21 \%$ & 1.886 & 18.648 \\
\hline
\end{tabular}

As stated earlier, the cost analysis was performed from the perspective of how expensive it would be to upgrade traditional $2 \times 4$ and $2 \times 6$ walls to match the energy performance of the $2 \times 6$ wall insulated with PCM-enhanced cellulose. Earlier correlations developed between wall Rvalues and wall-generated loads were used in this analysis. With the use of a regression equation presented in Figure 36, R-value equivalents were computed for the scenario considered. New R- 
value equivalents, together with calculated $\mathrm{R}$-value differences from the $\mathrm{R}$-values of nominal $2 \times 4$ and $2 \times 6$ walls, are presented in Table 7 .

Table 7. R-value equivalents and R-value differences calculated for the scenario considered

\begin{tabular}{|c|c|c|c|c|}
\hline $\begin{array}{c}\text { Nominal } \\
\text { R-value of } \\
\text { analyzed } \mathbf{2 \times 4} \\
\text { wall }\end{array}$ & $\begin{array}{c}\text { Nominal } \\
\text { R-value of } \\
\text { analyzed } 2 \times \mathbf{6} \\
\text { wall }\end{array}$ & $\begin{array}{c}\text { R-value } \\
\text { equivalent }\end{array}$ & $\begin{array}{c}\text { R-value difference } \\
\text { from nominal } \mathbf{2 \times 4} \\
\text { wall R-value }\end{array}$ & $\begin{array}{c}\text { R-value difference } \\
\text { from nominal } \mathbf{2 \times 6} \\
\text { wall R-value }\end{array}$ \\
\hline 12.65 & 16.80 & 21.16 & 8.51 & 4.36 \\
\hline
\end{tabular}

In the next step, based on computed R-value equivalents, the authors determined the cost of a thermal upgrade of the nominal $2 \times 4$ or $2 \times 6$ walls to an R-value level generating the same cooling loads that would be achieved with application of PCM-enhanced cellulose insulation. Fictitious layers of sheathing insulation made of XPS foam (with a nominal thermal resistivity of R-5 per inch) were analyzed to determine the cost associated with the necessary R-value improvements. In each case, the calculated thickness of the foam sheathing was rounded to the closest $1 / 4$ in. The approximate cost of the foam sheathing was estimated as $\$ 0.117$ per $\mathrm{R}$, based on the data provided by the National Association of Home Builders for $1 / 2$ in thick XPS foam board (NAHB 2003). The installation cost for the foam sheathing was considered as $\$ 0.24$ (Means 2005). For 2007 , that is a very conservative estimate considering that the labor cost in the United States has been increasing by about $4 \%$ per year, according to U.S. Bureau of Labor data. Also, R.S. Means reported the labor cost only for 1 in. thick XPS foam sheathing.

In this project, additional costs related to necessary adaptations of building openings (windows and doors) to non-typical wall thicknesses were not analyzed. Table 8 presents the calculated thicknesses of the XPS foam insulation that it would be necessary to install to reach the required R-value improvement. Table 9 summarizes the costs of materials and installation.

Table 8. Calculated thicknesses of extra XPS foam insulation

\begin{tabular}{|c|c|c|c|c|}
\hline $\begin{array}{c}\text { Nominal } \\
\text { R-value of analyzed }\end{array}$ & $\begin{array}{c}\text { Nominal } \\
\text { R-value of } \\
\text { analyzed } 2 \times 6 \\
\text { wall }\end{array}$ & $\begin{array}{c}\text { R-value } \\
\text { equivalent }\end{array}$ & $\begin{array}{c}\text { Computed } \\
\text { necessary thickness } \\
\text { of XPS foam for } \\
2 \times 6 \text { wall (in.) }\end{array}$ & $\begin{array}{c}\text { Computed } \\
\text { necessary thickness } \\
\text { of XPS foam for } \\
2 \times 4 \text { wall (in.) }\end{array}$ \\
\hline 12.65 & 16.80 & 21.16 & 1.0 & 1.75 \\
\hline
\end{tabular}

Table 9. Calculated cost of extra XPS foam insulation

\begin{tabular}{|c|c|c|c|c|}
\hline $\begin{array}{c}\text { Computed cost of } \\
\text { extra XPS foam } \\
\text { for } 2 \times 6 \text { wall } \\
\left(\$ \text { per } \mathrm{ft}^{2}\right)\end{array}$ & $\begin{array}{c}\text { Computed cost } \\
\text { of extra XPS } \\
\text { foam for } 2 \times 4 \\
\text { wall } \\
\left(\$ \text { per } \mathrm{ft}^{2}\right)\end{array}$ & $\begin{array}{c}\text { Cost } \\
\text { of labor } \\
\left(\$ \text { per } \mathrm{ft}^{2}\right)\end{array}$ & $\begin{array}{c}\text { Computed cost of } \\
\text { installed XPS foam } \\
\text { for } 2 \times 6 \text { wall } \\
\left(\$ \text { per } \mathrm{ft}^{2}\right)^{a}\end{array}$ & $\begin{array}{c}\text { Computed cost of } \\
\text { installed XPS foam } \\
\text { for } 2 \times 4 \mathrm{wall} \\
\left(\$ \mathrm{per} \mathrm{ft}^{2}\right)^{a}\end{array}$ \\
\hline 0.67 & 1.08 & 0.24 & 0.91 & 1.32 \\
\hline
\end{tabular}
Additional costs related to necessary adaptations of building openings (windows and doors) to non-typical wall
thicknesses were not included.

As stated earlier, the cost of cellulose fiber insulation was estimated based on data provided by the Knoxville, TN, Lowe's store, and the cost of the PCM-enhanced cellulose was estimated 
based on cost predictions from U.S. Green Fiber and Advanced Fiber Technology (the two companies represent over $60 \%$ of the North American cellulose insulation market).

In the whole-building energy simulations described above, it was assumed that foam insulation would cover $100 \%$ of the opaque wall area. At the same time, about $20 \%$ of the areas of both analyzed wall configurations $(2 \times 4$ and $2 \times 6)$ consisted of framing members, which yields a $20 \%$ lower net area for cavity insulation.

Data presented in Tables 3 and 9 are combined in Figure 37 to visualize the cost differences between traditional insulation methods and application of PCM-enhanced cellulose insulation. Figure 37 presents the results of a cost analysis for installation of PCM-enhanced cellulose insulation versus thermally equivalent traditionally insulated $2 \times 4$ and $2 \times 6$ walls. Based on the data presented in Figure 37, it is evident that when it comes to reduction of cooling loads, PCMenhanced cellulose insulation is significantly less costly than traditional methods of improving wall R-value by using foam sheathing.

The cost analysis presented is very conservative. Extra costs associated with necessary adaptations of the building openings (windows and doors) to non-typical wall thicknesses after

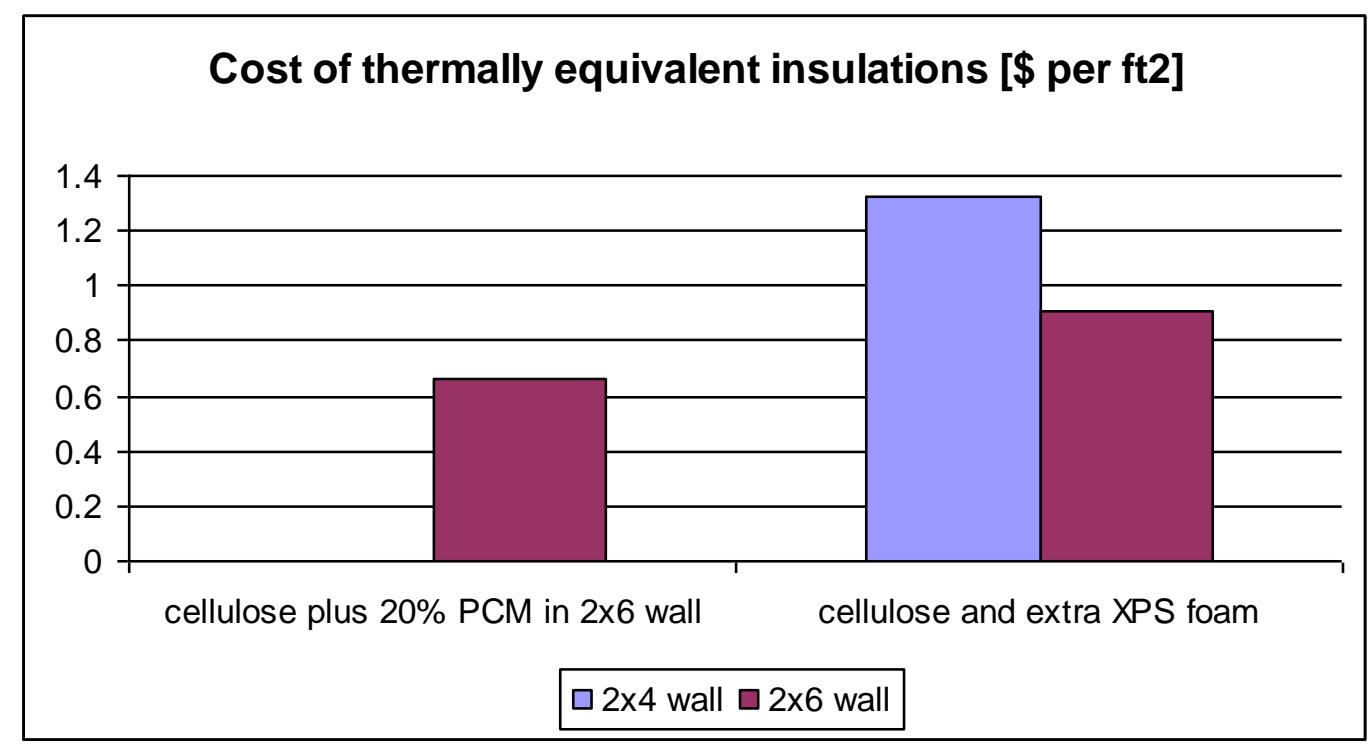

Figure 37. Comparative costs of installing fiber insulation and XPS foam sheathing and thermally equivalent PCM-enhanced cellulose insulation

installation of the foam sheathing were not considered. Also, because incentives that might be offered by utility companies for houses containing PCM were unknown, potential cost benefits associated with peak-hour load reductions were not evaluated in this project. 


\section{CONCLUSIONS}

Microencapsulated paraffinic material can be mixed with conventional loose-fill cellulose insulation and installed in residential wall cavities without major modifications of the manufacturing or installation processes.

The installation of PCM-cellulose mixtures in wall cavities reduces the heat flow across the cavities due to fluctuating temperature changes on one side. The observed reduction was $40 \%$ for the dynamic hot-box tests that were completed.

Reductions in summer cooling loads and winter heating loads were observed for wall cavities in South Carolina and Tennessee that were insulated with cellulose containing 22 wt \% microencapsulated PCM.

Reduction of cooling-dominated loads averaged $42 \%$ for PCM-insulated cavities at the Tennessee site. Mixed and heating-dominated loads were reduced by $16 \%$ at the Tennessee site. A 5\% cooling-load reduction was observed for wall cavities insulated with PCM at the South Carolina site.

Peak-hour load reductions of $30 \%$ were observed for PCM-insulated walls at the South Carolina site during the summer months.

A preliminary economic analysis of an application of PCM-enhanced insulation in residential buildings shows a potential for cost reduction compared with traditional insulation methods using foam sheathing.

\section{REFERENCES}

ASTM (American Society of Testing and Materials) 2006. "Standard Test Method for SteadyState Thermal Transmission Properties by Means of the Heat Flow Meter Apparatus," ASTM C518.

ASTM (American Society of Testing and Materials) 2006. "Standard Specification for Cellulosic Fiber Loose File thermal Insulation” (Smoldering Combustion Test), ASTM C739.

Balcomb, J. D., R. W. Jones, C. E. Kosiewicz, G. S. Lazarus, R. D. McFarland, and W. O Wray 1983. Passive Solar Design Handbook, ISBN 0-89553-124-0, American Solar Energy Society Inc.

Duffie, J. A., and W. A. Beckman 1980. Solar Engineering of Thermal Processes, John Wiley and Sons, New York.

Feustel, H. E. 1995. Simplified Numerical Description of Latent Storage Characteristics for Phase Change Wallboard, Indoor Environmental Program Energy and Environment Division, Lawrence Berkeley National Laboratory. 
Hasting, S. R. 1977. "Three Proposed Typical House Designs for Energy Conservation Research," NBSIR 77-1309, National Bureau of Standards, Gaithersburg, MD.

Huang, Y. J., J. Ritschard, S. Bull, I. Byrne, D. Turiel, D. C. Wilson, H. Sui, and D. Foley 1987. Methodology and Assumptions for Evaluating Heating and Cooling Energy Requirements in New Single-Family Residential Buildings, Technical Support Document for the PEAR Microcomputer Program, LBL-19128, Lawrence Berkeley Laboratory, Berkeley, CA.

Kissock, J. Kelly, J. Michael Hannig, and Thomas I. Whitney 1998. "Testing and Simulation of Phase Change Wallboard for Thermal Storage in Buildings," in Proceedings of 1998

International Solar Energy Conference, June 14-17, Albuquerque, J. M. Morehouse and R. E. Hogan, Eds., American Society of Mechanical Engineers, New York.

Kosny, J., D. Gawin, and A. Desjarlais 2001. "Energy Benefits of Application of Massive Walls in Residential Buildings," in Proceedings of Thermal Envelopes VIII, Clearwater, FL, December 2001.

Kosny, J., David Yarbrough, and Kenneth Wilkes 2006. "PCM-Enhanced Cellulose Insulation: Thermal Mass in Light-Weight Fibers," International Energy Agency and Department of Energy Ecostock 2006 Conference, Stockton University, May 31, 2006

Kossecka, E. and J. Kosny 1997. "Equivalent Wall as a Dynamic Model of Complex Thermal Structure," Journal of Thermal Insulation and Building Envelopes 20, January.

Means, R.S., 2005. “Residential Cost Data,” Kingston, MA.

NAHB (National Association of Home Builders Research Center) 2003. Alternatives to Structural Plywood and OSB, found at http://www.toolbase.org/ToolbaseResources/level4DG.aspx?ContentDetailID=1166\&BucketID= $\underline{4 \& \text { CategoryID }=7}$.

Petrie, T. W., K. W. Childs, P. W. Childs, J. E. Christian, and D. J. Shramo 1997. "Thermal Behavior of Mixtures of Perlite and Phase Change Material in a Simulated Climate," pp. 180194 in Insulation Materials: Testing and Applications: Third Volume, ASTM STP 1320, R.S. Graves and R.R. Zarr, Eds., American Society for Testing and Materials, West Conshohocken, PA.

Salyer, I., and A. Sircar 1989. "Development of PCM Wallboard for Heating and Cooling of Residential Buildings," pp. 97-123 in Thermal Energy Storage Research Activities Review, U.S. Department of Energy, New Orleans, March 15-17, 1989.

Stovall, T. K., and J. J. Tomlinson 1995. "What are the Potential Benefits of Including Latent Storage in Common Wallboard?" Journal of Solar Energy Engineering 11.

Thom, H. C. S. 1954. "Normal Degree-Days below Any Base," Monthly Weather Review, 82, May, 111-115. 
Tomlinson, J., C. Jotshi, and D. Goswami 1992. "Solar Thermal Energy Storage in Phase Change Materials," pp. 174-79 in Proceedings of Solar '92: The American Solar Energy Society Annual Conference, June 15-18, 1992, Cocoa Beach, FL.

Zhang, Meng, M. A. Medina, and Jennifer King 2005. "Development of a Thermally Enhanced Frame Wall With Phase-Change Materials for On-Peak Air Conditioning Demand Reduction and Energy Savings in Residential Buildings," International Journal of Energy Research 29(9), 795-809. 